\title{
Molten Silicate Reactions with Plasma Sprayed Ytterbium Silicate Coatings
}

\author{
Hengbei Zhao ${ }^{1}$, Bradley T. Richards ${ }^{1}$, Carlos G. Levi ${ }^{2}$, Haydn N.G. Wadley ${ }^{1}$ \\ ${ }^{1}$ Department of Materials Science and Engineering, \\ University of Virginia, Charlottesville, VA 22904 \\ ${ }^{2}$ Materials Department, University of California, Santa Barbara, CA 93106-5050
}

\begin{abstract}
The reactions between molten calcium aluminum magnesium silicates (CMAS) at $1300^{\circ} \mathrm{C}$ and atmospheric plasma spray (APS) deposited environmental barrier coatings on $\mathrm{SiC}$ substrates have been investigated. The tri-layer coatings comprised a silicon bond coat protected by a layer of mullite and either $\mathrm{Yb}_{2} \mathrm{SiO}_{5}$ (ytterbium monosilicate, $\mathrm{YbMS}$ ) or $\mathrm{Yb}_{2} \mathrm{Si}_{2} \mathrm{O}_{7}$ (ytterbium disilicate, YbDS) as the topcoat. The APS deposition process resulted in two-phase top coats; the YbMS coating contained $\mathrm{Yb}_{2} \mathrm{O}_{3}$ regions in a matrix of $\mathrm{Yb}_{2} \mathrm{SiO}_{5}$ while the $\mathrm{YbDS}$ coating contained $\mathrm{Yb}_{2} \mathrm{SiO}_{5}$ in a matrix of $\mathrm{Yb}_{2} \mathrm{Si}_{2} \mathrm{O}_{7}$. Exposure of both coatings to a model CMAS resulted in dissolution of the topcoat accompanied by a rapid rise in the concentration of $\mathrm{Yb}$ in the melt, and formation of the same $\mathrm{Ca}_{2} \mathrm{Yb}_{8}\left(\mathrm{SiO}_{4}\right)_{6} \mathrm{O}_{2}$ apatite reaction product phase. The thickness of the apatite layer initially varied with (time) ${ }^{1 / 4}$, but transitioned to approximately parabolic kinetics after 5-10 hours of CMAS exposure. The reaction mechanism on the YbMS layer was consistent with recent observations on $\mathrm{Y}_{2} \mathrm{SiO}_{5}$, wherein molten CMAS transport to the undissolved silicate was controlled by diffusion through thin amorphous films at the apatite grain boundaries. The reaction mechanism for the YbDS layer was more complex, and involved preferential reaction with the $\mathrm{YbSiO}_{5}$ rich regions, resulting in a reaction zone that contained CMAS, the apatite reaction compound and undissolved $\mathrm{Yb}_{2} \mathrm{Si}_{2} \mathrm{O}_{7}$. The coating composition and microstructure significantly influenced the mechanism and rate at which the YbDS top coat was consumed by the reaction.
\end{abstract}

Keywords: Environmental Barrier Coatings; CMAS; Atmospheric Plasma Spray Deposition 


\section{Introduction}

Efforts to increase the combustion temperature of the most advanced gas turbine engines has stimulated interest in the use of ceramic components with much higher maximum use temperatures than conventional superalloys [1-3]. Since silicon carbide based ceramic matrix composites (CMCs) offer a superior high temperature strength and crack growth resistance compared to most other ceramic candidates [3], they are the currently preferred material for future engines. $\mathrm{SiC}$ also has excellent resistance to oxidation at high temperature in dry air owing to the formation of an adherent, thermally grown oxide (TGO) [3]. However, in the moist combustion environment, the $\mathrm{SiO}_{2}$ TGO reacts with water vapor to form gaseous silicon hydroxides such as $\mathrm{Si}(\mathrm{OH})_{4}$, resulting in rapid volatilization under the high gas temperature/pressure/velocity environment within an engine combustor and high pressure turbine [4-6]. Since engine components are normally expected to survive for several thousand hours of operation [7], those made from SiC-based CMCs must be protected from oxidation and volatilization by environmental barrier coating systems (EBC's) [1, 3].

While EBCs must be resistant to volatilization by the water vapor present in the combustion environment, they must also be free of pores and cracks to remain effective barriers to the transport of oxygen and water vapor to the SiC surface. Their coefficient of thermal expansion (CTE) must be well matched with the substrate to minimize thermal stresses that can lead to coating cracking or delamination during thermal cycling and thermal shock loading. They must also be able to resist degradation by molten silicates, generically known as CMAS for their major constituents $\left(\mathrm{CaO}, \mathrm{MgO}, \mathrm{Al}_{2} \mathrm{O}_{3}\right.$, and $\left.\mathrm{SiO}_{2}\right)$, which are deposited on hot coating surfaces during service.

Current generation EBCs use a silicon bond coat applied to the SiC substrate and an outer layer based on a rare earth (RE) silicate, notably one of those based upon Y or Yb. The coating layers are typically applied by atmospheric plasma spray (APS) deposition. While the disilicates $\left(\mathrm{RE}_{2} \mathrm{Si}_{2} \mathrm{O}_{7}\right)$ are thermochemically compatible with the thermally grown $\mathrm{SiO}_{2}$ that from on the $\mathrm{Si}$ bond coat, and have a CTE reasonably close to that of $\mathrm{SiC}$, they have a substantially higher $\mathrm{SiO}_{2}$ activity (and faster steam volatility) than their monosilicate counterparts $\left(\mathrm{RE}_{2} \mathrm{SiO}_{5}\right)$ [3, 8, 9]. However, the monosilicates have a higher CTE than the substrate [10], and if allowed to contact the thermally grown $\mathrm{SiO}_{2}$ on a silicon bond coat, would react to form a disilicate, potentially 
compromising the adherence of the $\mathrm{EBC}$. In principle, the $\mathrm{EBC}$ could be designed to have the disilicate in contact with the $\mathrm{SiO}_{2}$, covered by a thinner layer of monosilicate in contact with the atmosphere. However, a layer of mullite has sometimes been used instead to delay thermochemical interactions between the thermally grown silica on the Si bond coat, and the RE silicate top coat [11].

Environmental barrier coatings are vulnerable to chemical reactions with molten silicates (CMAS) [12-14]. These molten silicates are ingested as solid dust particles with the engine intake air and partially or totally melt above a temperature of $\sim 1200^{\circ} \mathrm{C}$ [15]. This temperature is first encountered as the particles travel through the combustor, resulting in molten particle impacts with hot component surfaces in this region of the engine, and in the high-pressure turbine. Because EBCs are nominally dense and approximately CTE matched to the substrate, the molten silicate problem is predominantly thermochemical, rather than thermomechanical as in thermal barrier coatings [16, 17]. In essence, the EBC is dissolved by the molten glass and may reprecipitate reaction products that are less CTE compatible with the substrate or exhibit a higher tendency for volatilization. Earlier generation barium strontium aluminum silicates (BSAS) based EBC's were found to be highly susceptible to degradation by CMAS [18], not only by dissolution of the EBC, but also by penetration of the glass along grain boundaries well beyond the dissolution front [18].

Grant et al. [12] showed that CMAS could cause significant recession of yttrium monosilicate $\left(\mathrm{Y}_{2} \mathrm{SiO}_{5}\right.$, YMS). Using fully dense powder coupons and a model CMAS (33CaO$9 \mathrm{MgO}-13 \mathrm{AlO}_{1.5}-45 \mathrm{SiO}_{2}$ ) with an incipient melting point of $1233^{\circ} \mathrm{C}$ [19], they observed rapid recession $\left(\sim 100 \mu \mathrm{m}\right.$ in $100 \mathrm{~h}$ at $\left.1300^{\circ} \mathrm{C}\right)$, in spite of the formation of a nearly dense $\mathrm{Ca}_{2} \mathrm{Y}_{8}\left(\mathrm{SiO}_{4}\right)_{6} \mathrm{O}_{2}$ oxyapatite layer at the YMS surface. The continued reaction was enabled by thin amorphous layers at the grain boundaries within the oxyapatite layer, which provided a fast path for diffusion to the YMS-apatite reaction front. They postulated that yttrium disilicate (YDS) coatings might be less effective at mitigating the reaction with CMAS since more YDS cations would be needed (consumed) to form a unit amount of the reaction product. While Ahlborg and Zhu investigated the reactions of hot pressed samples of YbMS and YbDS with CMAS at $1500^{\circ} \mathrm{C}$, [13] and noted the formation of $\mathrm{Ca}_{2} \mathrm{Yb}_{8}\left(\mathrm{SiO}_{4}\right)_{6} \mathrm{O}_{2}$ apatite in both systems, they did not investigate the mechanisms or the rates of the reactions. 
Thermal spray methods have been developed and recently optimized for depositing EBC systems comprising a silicon bond coat and either ytterbium monosilicate $\left(\mathrm{Yb}_{2} \mathrm{SiO}_{5}, \mathrm{YbMS}\right)$ or ytterbium disilicate $\left(\mathrm{Yb}_{2} \mathrm{Si}_{2} \mathrm{O}_{7}, \mathrm{YbDS}\right)$ top coats [10, 20-22]. An interlayer of thermally sprayed mullite was added under the YbMS to prevent interactions with the $\mathrm{SiO}_{2}$ that forms on the silicon bond coat surface. While YbDS is not expected to interact with $\mathrm{SiO}_{2}$, mullite was also added to this system as well because the spray deposited coating was not phase pure. Prior work revealed that stoichiometric YbMS and YbDS powders experience a loss of $\mathrm{SiO}_{2}$ during APS deposition, resulting in $\mathrm{YbMS}$ coatings that containing $\mathrm{Yb}_{2} \mathrm{O}_{3}$ as a segregate phase, and $\mathrm{YbDS}$ coatings that contained $\mathrm{Yb}_{2} \mathrm{SiO}_{5}[10]$. The previous studies $[12,13]$ have examined CMAS reactions using sintered test coupons of nominally phase pure materials. However, since, the EBC systems that will be used in practice are likely to be deposited by a thermal spray methods, it is possible that the interaction of CMAS with EBCs could be significantly influenced by the morphology of the spray deposited coating. This investigation therefore seeks to characterize the mechanisms and rate of the reaction between molten CMAS and APS deposited tri-layer EBC's with both YbMS and YbDS top coats.

\section{Experiments}

Three-layer YbMS/mullite/silicon and YbDS/mullite/silicon EBCs were deposited by APS onto rectangular $2.54 \mathrm{~cm} \times 1.27 \mathrm{~cm} \times 0.32 \mathrm{~cm} \alpha-S i C$ substrate coupons obtained from Hexoloy $^{\mathrm{TM}}$ (Saint Gobain Ceramics, Niagara Falls, NY). Prior to EBC deposition, the substrates were grit blasted using $270 \mu \mathrm{m}$ diameter SiC grit (Black SiC, White Abrasives, Niagara Falls, $\mathrm{ON})$ resulting in an average surface roughness of $\sim 1 \mu \mathrm{m}$. The substrates were then ultrasonically cleaned in ethanol to remove surface contamination. The silicon bond coat was deposited using sieved silicon powder with a particle diameter range of 44 to $149 \mu \mathrm{m}$ obtained from Micron Metals (Bergenfield, NJ). The mullite powder was obtained from Saint Gobain Ceramics (Worcester, MA), and had a particle diameter of 16 to $53 \mu \mathrm{m}$. The $\mathrm{Yb}_{2} \mathrm{SiO}_{5}$ and $\mathrm{Yb}_{2} \mathrm{Si}_{2} \mathrm{O}_{7}$ powders were provided by Treibacher Industrie Inc. (Toronto, ON) and had particle diameter distributions of 20 to $50 \mu \mathrm{m}$. Powders were identified by the respective manufacturers as fully reacted and phase pure, and this was confirmed by x-ray diffraction and SEM examinations of sectioned and polished surfaces. 
The coatings were deposited using a Praxair-TAFA UPC 7700 controlled APS system with a SG-100 torch with a model 02083-175 anode, model 02083-120 cathode, and model 03083-112 gas injector. All coating layers were deposited at $1200^{\circ} \mathrm{C}$ within a furnace. The detailed deposition set up was identical to that recently described elsewhere [20, 21]. The substrate was first heated to the prescribed temperature inside a box furnace containing a small aperture through which the APS plume was introduced. A reducing gas flow within the furnace was used to inhibit oxidation of the $\mathrm{SiC}$ substrate and the Si bond coat during its deposition. The flow rate of the reducing gas was $20 \mathrm{slm}$ with a volume ratio of $\mathrm{Ar}: \mathrm{H}_{2}$ of 20:1. Immediately after deposition of the Si layer, the reducing gas flow was stopped, and the two subsequent layers were deposited at $1200^{\circ} \mathrm{C}$. The spray parameters for YbMS and YbDS coatings are described elsewhere [10]. Both the YbMS and YbDS coatings had an average thickness of $100 \mu \mathrm{m}$ with a variation of $36-120 \mu \mathrm{m}$ for YbMS and 42-126 $\mu \mathrm{m}$ for YbDS. The weight of the deposited topcoats was measured as $\sim 110 \mathrm{mg}$ for YbMS and $\sim 94 \mathrm{mg}$ for YbDS. The mullite and silicon layers were both nominally $75 \mu \mathrm{m}$ in thickness. Since a variety of metastable phases form during the deposition of tri-layer coatings [22], the "as deposited" samples were annealed at $1300^{\circ} \mathrm{C}$ for 20 hours in lab air to stabilize their microstructure. All of the molten silicate tests and microstructural characterizations were performed on these "stabilized coating" samples.

The coated samples were subjected to a CMAS test protocol similar to that developed for previous studies of $\mathrm{TBC}$ and $\mathrm{EBC}$ reactions [12, 16, 23]. The model CMAS (with the composition $33 \mathrm{CaO}-9 \mathrm{MgO}-13 \mathrm{AlO}_{1.5}-45 \mathrm{SiO}_{2}$ (mole percent), or $\mathrm{C}_{33} \mathrm{M}_{9} \mathrm{~A} 1_{13} \mathrm{~S}_{45}$ ) used by Grant et al [18] was adopted here to enable direct comparison with the YMS studies. The melting range for this CMAS composition was $1233^{\circ} \mathrm{C}-1249^{\circ} \mathrm{C}$ [19]. The CMAS was prepared by ball milling $\mathrm{CaO}, \mathrm{MgO}, \mathrm{Al}_{2} \mathrm{O}_{3}$ and $\mathrm{SiO}_{2}$ powders followed by reaction sintering at $1200^{\circ} \mathrm{C}$ for 20 hours. The composition of the CMAS after reaction of the powdered constituent oxides has been measured in a scanning electron microscope (SEM) using energy dispersive spectroscopy (EDS), and is shown in Table 2.

The CMAS testing consisted of cold-pressing pre-reacted CMAS powder into a pellet $\sim 5 \mathrm{~mm}$ in diameter with a mass of $\sim 30-35 \mathrm{mg}$. The pellet was placed on the surface of the coated samples at ambient temperature, and then heated in air at a rate of $10^{\circ} \mathrm{C} / \mathrm{min}$ to $1300^{\circ} \mathrm{C}$. The samples were held at this temperature for varying times followed by furnace cooling at a rate of 
$10^{\circ} \mathrm{C} / \mathrm{min}$ to ambient temperature. The specimens were then sectioned, mounted in epoxy and polished, using a $0.5 \mu \mathrm{m}$ diameter diamond suspension for the final step. Backscattered electron (BSE) images and the compositions of various phases were obtained using a scanning electron microscope (FEI Quanta 600 FEG) equipped with Bruker QUANTAX 400 energy dispersive Xray spectrometer (EDS). Transmission electron microscopy (TEM) specimens were prepared from the areas of interest by a "lift-out" technique using a FEI Helios 600 dual-beam FIB microscope. The TEM samples were examined in a JEOL 2000FX $200 \mathrm{keV}$ transmission electron microscope.

\section{Results}

\subsection{Coating microstructure}

Figure 1 shows the BSE images of the as-deposited and annealed tri-layer coatings with YbMS, Figure 1 (a) and (c), and YbDS, Figure 1 (b) and (d), top coats. The top coats of both coating systems were nearly pore free. However, the YbMS layer contained periodic channel cracks with a spacing of $\sim 200 \mu \mathrm{m}$, while the YbDS coatings contained only small microcracks in regions of lighter contrast (higher Yb concentration), Figure 1(d). The YbMS channel cracking has been previously shown to arise because its coefficient of thermal expansion $\left(\sim 7.4 \mathrm{ppm} /{ }^{\circ} \mathrm{C}\right)$ is higher than that of the $\mathrm{SiC}$ substrate $\left(4.5-5.5 \mathrm{ppm} /{ }^{\circ} \mathrm{C}\right)[22]$. Stabilization annealing at $1300^{\circ} \mathrm{C}$ enables creep relaxation of the coating stresses and the development of a large biaxial tensile stress in the YbMS layer upon cooling. The resulting stored elastic strain energy then provides a driving force for the formation of (coating layer penetrating) channel cracks. The nominal CTE of the $\mathrm{YbDS}$ layer $\left(\sim 4.5 \mathrm{ppm} /{ }^{\circ} \mathrm{C}\right)[24]$ was much better matched to the substrate, and resulted in the development of a small compressive stress in the coating after cooling [25], with no channel cracking.

When imaged in BSE mode, Figures 1 (b) and (d), the YbMS and YbDS layers were seen to contain banded regions of lighter contrast that were depleted in low atomic number elements (Si and O). Previous studies on APS deposited coatings [20, 21] indicated the banded morphology was created by droplet spreading during deposition of the coating. The phases formed within the light and darker contrast regions of both coatings were investigated by TEM. The black box areas in Figures 1(c, d) mark the location of the FIB lamella extracted for TEM. A 
bright field image of area A in the YbMS coating is shown in Figure 2(a). Second phase segregates can be clearly seen in the banded zone. The compositions of the segregates (of darker contrast) and the matrix (lighter gray) have been listed in Table 1. The results indicate that the second phase particles have a composition close to $\mathrm{Yb}_{2} \mathrm{O}_{3}$, while the matrix is very close to $\mathrm{Yb}_{2} \mathrm{SiO}_{5}$. Selected area electron diffraction (SAED) patterns from the matrix are shown in Figure 2(c) and (d) and from a segregate particle in Figure 2(e). The indexed diffraction patterns indicate that the matrix has a monoclinic structure while the particle is the cubic phase of $\mathrm{Yb}_{2} \mathrm{O}_{3}$.

Figure 3 shows bright field TEM images of the annealed YbDS coating collected from the two-phase region corresponding to area B in Figure 1(d). A magnified view of one of the second phase particles is shown in Figure 3(b). The EDS compositions of the particle and the matrix (measured at locations marked with crosses) are presented in Table 1. The results indicate that the matrix has a $\mathrm{Yb}: \mathrm{Si}$ atomic ratio of $\sim 1: 1$ while that of the particles was approximately 2:1. This is consistent with YbMS segregation from a $\mathrm{SiO}_{2}$ depleted $\mathrm{YbDS}$ melt during deposition. The SAED patterns of the segregate confirm this finding. Figures 3 (c) and (d) correspond to the [11] and $[01 \overline{1}]$ zone axes of the monoclinic $\mathrm{Yb}_{2} \mathrm{SiO}_{5}$ phase, respectively. The microcracks present in the lighter contrast region are therefore consistent with local shrinkage due to the higher CTE of YbMS.

\subsection{YbMS-CMAS reaction}

The evolution of the CMAS/YbMS reaction with increasing exposure time is shown in Figure 4. All of the samples exhibited channel cracks upon cooling from $1300^{\circ} \mathrm{C}$ with many of the cracks extending through the solidified CMAS. The CMAS had melted and spread over the coating surface as the samples were heated to $1300^{\circ} \mathrm{C}$ which was well above the CMAS melting range of $\sim 1233-1249^{\circ} \mathrm{C}[19]$. A thin and continuous layer of reaction product between the melt and the YbMS was observed even for exposure times at $1300{ }^{\circ} \mathrm{C}$ as short as $1 \mathrm{~min}$, Figure 4(a). A FIB milling and lift-out operation was performed on the YbMS reaction layer formed after the YbMS was exposed to CMAS for $4 \mathrm{~h}$ at $1300^{\circ} \mathrm{C}$, Figure 5(a). A bright field image of a reaction product grain is shown in Figure 5(b). The SAED patterns of the reaction phase are shown in Figure 5(c) and (d), and correspond to the [001] and [021] zone axes of a hexagonal apatite phase similar to that found in YMS [12]. The lattice parameters of the apatite phase were calculated as $\mathrm{a}=\mathrm{b}=9.32 \AA$ and $\mathrm{c}=6.36 \AA$ which are reasonably matched with the reference lattice of $\mathrm{a}=\mathrm{b}=9.31 \AA$ 
and $c=6.72 \AA$ for hexagonal $\mathrm{Ca}: \mathrm{Yb}$ apatite [26]. A TEM/EDS composition analysis of the grain, Table 4, is reasonably consistent with the nominal composition of the oxyapatite $\mathrm{Ca}_{2} \mathrm{Yb}_{8}\left(\mathrm{SiO}_{4}\right)_{6} \mathrm{O}_{2}$, similar to that formed by the reaction of CMAS with RE zirconates [16, 27] and YMS [12].

Careful examination of the micrographs in Figure 4 revealed little evidence of locations where the reaction might have taken place at a significantly different rate, such as at $\mathrm{Yb}_{2} \mathrm{O}_{3}$ segregates. EDS line scan analyses of the CMAS melt for different infiltration times have been included in Figures 4(a), (d) and (f). They indicate that the CMAS melt contained approximately 7.5 mole $\% \mathrm{YbO}_{1.5}$ and remained at this concentration as the exposure time was increased, up to the $250 \mathrm{~h}$ experimental limit. This is consistent with the dissolution of approximately $10 \mu \mathrm{m}$ $(\sim 11 \mathrm{mg})$ of the $\mathrm{Yb}_{2} \mathrm{SiO}_{5}$ coating in the original volume of CMAS melt.

Determination of the rate at which the apatite formed was complicated by the presence of residual CMAS within the crystalline phases. However, its difference in average atomic number contrast enabled the area fraction of the apatite to be determined. This was then divided by the width of the image to determine an "equivalent" thickness of the reaction product layer. This "equivalent" thickness, which is an indirect measure of the YbMS surface recession rate, was found to increase over time, Figure 6. For exposure times of $<10$ hours, the thickness data could be fitted by a power law of the form; $\mathrm{h}(\mathrm{t})=\mathrm{kt} \mathrm{t}^{\mathrm{n}}$ where $\mathrm{h}$ is the equivalent thickness (in $\left.\mu \mathrm{m}\right), \mathrm{n}=1 / 4$ is the power law exponent, $\mathrm{t}$ is the time (hours) and $\mathrm{k}$ is a rate constant with units of $\mu \mathrm{m}$ (hour) ${ }^{1 / \mathrm{n}}$. Data for samples subjected to more prolonged exposures could also be fitted to a power law, but with and an exponent $n=1 / 2$, and a slightly different (parabolic) rate constant, Figure 6.

Chemical composition profiles within the reaction layer were obtained from EDS line scans normal to the substrate surface, Figure 7. The CMAS reaction depth was clearly differentiated by the contrast difference between the apatite and the unreacted YbMS in BSE imaging. The $\mathrm{Ca}, \mathrm{Mg}$ and $\mathrm{Al}$ concentrations dropped below the level of EDS detection in the unreacted region of the YbMS coating, indicating that solid state (including grain boundary) diffusion of these elements in the almost fully dense coating was negligible at $1300^{\circ} \mathrm{C}$. The average compositions of the CMAS melt located in pockets between the apatite grains, as well as in the residual CMAS well above the reaction zone, have been measured and are summarized in Table 2, along with the initial composition and that estimated after saturation with $\mathrm{Yb}$. It is 
noted that $\mathrm{Ca}$ in the CMAS melt was depleted as the reaction time increased, and was accompanied by an increase in concentration of the non-reacting $\mathrm{Al}$, while the Si concentration slightly decreased but then increased abnormally following a 250h exposure time. The amount of $\mathrm{YbO}_{1.5}$ in the pockets within the reaction zone was 5-6 mole \%; slightly less than that in the CMAS melt $\left(\sim 7.5\right.$ mole $\left.\% \mathrm{YbO}_{1.5}\right)$, consistent with local depletion of $\mathrm{Yb}^{3+}$ cations dissolved in the CMAS. This composition difference has also been observed in the CMAS interaction with yttrium monosilicate [12], where it was argued that additional crystallization upon cooling resulted in the local depletion of the rare earth element near the reaction front.

Higher resolution SEM images of the interface between the YbMS and growing apatite are shown in Figure 8. A thin, denser (less CMAS entrained) layer of reaction product is evident at the interface with the YbMS in this figure. Fingers of unreacted YbMS were observed intruding into the apatite layer (typically well away from its grain boundaries), for distances up to $\sim 3 \mu \mathrm{m}$ from the macroscopic recession front, Figure $8(\mathrm{~d})$, (e) and (f). This was consistent with a gradual diffusion of reactants from the grain boundary to the grain interior. The denser layer of apatite transitioned into a thicker layer of large, elongated crystals interpenetrated by residual CMAS. The width of these crystals, and the volume fraction of CMAS between them, increased with distance above the interface. Bright field TEM images of the interfacial region, Figures 9(a) and (b) reveal gaps between the grains of apatite penetrated by a thin layer of amorphous material, which arguably provided pathways for continued transport of reactants from the bulk melt to the interface with the YbMS and byproduct transport in the opposite direction. The thickness of the denser reaction layer followed a power law dependence on time with an exponent of $\sim 1 / 4$, similar to that seen during the initial stages of the reaction, Figure 6 .

The width of the apatite grains in the plane of this dense layer also exhibited a two-stage power law behavior, Figure 10, with an earlier period of slower coarsening ( $n \sim 0.08)$ followed by a faster evolution ( $\mathrm{n} \sim 0.21$ ). Examination of the cross sections of coatings exposed to CMAS for 250 hours revealed the presence of occasional regions of full tri-layer coating penetration by the CMAS. This appeared to occur at locations where the initial YbMS coating was thinner, e.g. Figure 11(a). In some areas, the CMAS had fully penetrated the YbMS, mullite and silicon layers and vigorously reacted with the $\mathrm{SiC}$ substrate resulting in the formation of large voids presumably associated with $\mathrm{CO}$ release during reaction of CMAS with the SiC substrate. 


\subsection{YbDS CMAS reaction}

The evolution of the ytterbium disilicate coating to a similar molten CMAS exposure at $1300^{\circ} \mathrm{C}$ can be seen as a function of exposure time in Figure 12. Recall that the lighter contrast elongated regions in the top coat correspond to a YbMS segregate. No mud cracking of the YbDS top coat was observed even though cracks had formed in the CMAS above the top coat on cooling. These CMAS cracks resulted from the substantial CTE difference between CMAS and the rest of the system. Even though the vertical cracks entered the YbDS layer with an elastic modulus (170 GPa) identical to that of the YbMS [20], they were quickly arrested since this layer was under a state of weak biaxial compression $[20,21]^{1}$. As in the YbMS case, a reaction product layer was formed between the CMAS and the YbDS coating. Its morphology was much more irregular and less columnar than that seen on the YbMS surface, as can be inferred from a comparison of Figures 4 and 8 . The reaction product was again interpenetrated by CMAS.

A bright field TEM image of the reaction interface between YbDS and CMAS is shown in Figure 13. The chemical composition of the darker grains was determined by EDS, and is summarized in Table 3. The YbDS/CMAS reaction product had approximately the same composition as that of the YbMS/CMAS system (Table 3). The SAED patterns of the dark grains were indexed to the [021] and [210] zone axes of hexagonal oxyapatite with a nominal composition of $\mathrm{Ca}_{2} \mathrm{Yb}_{8}\left(\mathrm{SiO}_{4}\right)_{6} \mathrm{O}_{2}$.

An effective reaction layer thickness was calculated by image analysis, and is compared with the corresponding YbMS coating data in Figure 6. The dependence of the equivalent apatite thickness upon exposure time for YbDS was similar to that of YbMS and could be fitted by a power law with an exponent of $0.27(\sim 1 / 4)$ for exposure times of less than 4 hours and $\sim 1 / 2$ thereafter. However, the net apatite thickness for the YbDS coating was slightly less than that of YbMS at the longer exposure times. EDS line scan analyses of samples subjected to different CMAS reaction times, Figure 12(b), indicate that the CMAS melt above the reaction zone again contained approximately 7.5 mole\% $\mathrm{YbO}_{1.5}$. The average compositions of the CMAS melt located in pockets between the apatite grains, and in the CMAS reservoir well above the reaction

\footnotetext{
${ }^{1}$ The driving for vertical crack extension is the tensile elastic strain energy (proportional to the elastic modulus and the difference in CTE of the coating and substrate), and is resisted by the fracture toughness of the region in which fracture occurs.
} 
zone were also measured by EDS, and are summarized in Table 4. As with the YbMS case, the $\mathrm{Ca}$ concentration in the CMAS melt decreased as the reaction time increased, but in the YbDS case it was accompanied by a noticeable increase in the Si concentration. The Yb content within the CMAS pockets between apatite crystals above the dense layer was again less than that in the CMAS reservoir. Note that the evolving $\mathrm{MgO}$ concentration in the melt was slightly lower for YbDS than YbMS, although the changes in both cases are relatively small compared to the variation in the $\mathrm{AlO}_{1.5}$ content.

The morphology of the reaction product between CMAS and YbDS can be seen which in the BSE imaging mode SEM images of samples subjected to CMAS exposures of 1 and $100 \mathrm{~h}$, Figure 14(a) and (b). The morphology was quite different to that formed on YbMS, Figure 7. In the YbMS reaction case, a planar interface was formed between the growing columnar apatite and the YbMS layer. However, in the YbDS case, the apatite did not have a columnar morphology, and nothing resembling a planar interface at the multi-grain scale could be identified. Instead, the apatite within the coating adopted an approximately equiaxed, blocky morphology (see left center of Figure 14(b)), with the apatite crystals embedded in solidified CMAS. The reaction had intruded into the interior of the coating by reacting preferentially with the surface connected YbMS segregates. These intrusions then left peninsulas of less reacted YbDS between them. Prolonged exposure of the coating to molten CMAS, Figure 14(b) resulted in the coarsening of the apatite crystals $(50-100 \mu \mathrm{m})$. Those in the upper regions of the reaction layer often adopting a more elongated shape with distinct faceting.

When the CMAS exposure time was increased to $250 \mathrm{~h}$, the YbDS top coating began to be fully penetrated by the CMAS melt at locally thinner locations of the coating, Figure 11(b). In the YbMS case, Figure 11(a) the CMAS had fully penetrated the YbMS, mullite and silicon layers and had vigorously reacted with the $\mathrm{SiC}$ substrate resulting in gas pocket formation. In the YbDS case, the reaction had not progressed beyond the mullite layer, Figure 11(b). Close examination of this figure clearly shows a Ca-rich phase had formed in the CMAS, both within the region of penetration and in the CMAS above the coating. EDS measurements of the platelet morphology phase revealed it to be a calcium alumino-silicate with a composition ratio of $\mathrm{Ca}: \mathrm{Al}: \mathrm{Si}$ of $\sim 1: 2: 2$, consistent with anorthite $\left(\mathrm{CaAl}_{2} \mathrm{Si}_{2} \mathrm{O}_{8}\right)$. 


\section{Discussion}

The reactions between molten CMAS and APS deposited EBC's with either a YbMS or YbDS top coat have been investigated by interrupted isothermal testing at $1300^{\circ} \mathrm{C}$ using a model CMAS that was fully molten above $1250^{\circ} \mathrm{C}$. No evidence of CMAS penetration along the grain boundaries was found in either of the ytterbium silicates investigated here; an observation at variance with similar experiments conducted upon the BSAS system [18]. The reaction between YbMS and CMAS was generally consistent with observations on the analogous yttrium monosilicate (YMS) system [12]. In essence, both reactions lead to the initially rapid dissolution of the monosilicate and the precipitation of apatite with a composition close to the nominal stoichiometry $\mathrm{Ca}_{2} \mathrm{RE}_{8}\left(\mathrm{SiO}_{4}\right)_{6} \mathrm{O}_{2}(\mathrm{RE}=\mathrm{Y}$ or $\mathrm{Yb})$. The microstructural features of the reaction front are remarkably similar in the two silicates, notwithstanding the difference in their initial morphology. This comprised a dense assemblage of equiaxed grains for the consolidated YMS [12] and a typical APS splat microstructure for the YbMS, Figure 1(a) and (c), with a small (10$15 \%$ ) volume fraction of $\mathrm{Yb}_{2} \mathrm{O}_{3}$ second phase and limited porosity.

The reaction with YbMS began rapidly, as seen in Figure 4(a). A YbMS coating exposed to CMAS for as little as one minute resulted in the formation of a thin layer of reaction product on the coating surface. The accompanying $\mathrm{Yb}$ concentration data, Table 2, shows that the CMAS above this reaction product contained $\sim 7.5 \mathrm{~mol} \% \mathrm{YbO}_{1.5}$ and this concentration did not increased significantly over time. The inference is that the Yb supersaturation in the CMAS melt needed to form apatite was developed in the time required to ramp up the temperature from that for the onset of CMAS melting $\left(\sim 1233^{\circ} \mathrm{C}\right)$ to the prescribed hold temperature $\left(1300^{\circ} \mathrm{C}\right), \sim 7 \mathrm{~min}$. Note that the dissolution of sufficient YbMS to saturate the melt would dilute the concentrations of all other oxides, including $\mathrm{SiO}_{2}$ since $\mathrm{YbMS}$ has a lower $\mathrm{Si}$ content than the original melt (Table 2).

It is evident from Figure 4 that the overall thickness of the reaction layer increased with exposure time, with concomitant recession of the YbMS surface. Note, however, that the reaction layer was only dense at the interface with the YbMS, Figure 8. The growing apatite crystallites, initially with an average (in-plane) width of $\sim 400 \mathrm{~nm}$, were interpenetrated by a network of thin amorphous films at the grain boundaries, Figure 9(a), which enabled the transport of $\mathrm{Ca}$ and $\mathrm{Si}$ to the reaction front as schematically depicted in Figure 15(a). The upper 
part of the reaction layer, however, was more substantially interpenetrated by CMAS, and some of the apatite grains appear weakly connected with the main reaction layer, analogous to observations of the reaction with YMS [12]. Compositional analysis of the CMAS pockets within the reaction layer revealed an $\mathrm{YbO}_{1.5}$ concentration of $\sim 5.5 \mathrm{~mol} \%$; slightly lower than that of the bulk CMAS layer, but again essentially constant over time, Table 2. This lower concentration is consistent with the formation of additional apatite upon cooling, which locally depletes the $\mathrm{Yb}^{3+}$ concentration.

Table 2 also shows an initially rapid decline in the Ca concentration of the CMAS melt consistent with the growth kinetics of the $\mathrm{Ca}$ rich apatite reaction product. The initially faster loss of $\mathrm{Ca}$ was consistent with the time necessary to form a continuous apatite layer, and the shorter grain boundary diffusion distances through the nearly dense layer while it was relatively thin, Figure 6. It is notable that while the Ca concentration in the CMAS melt declined with exposure time, the CMAS $\mathrm{SiO}_{2}$ concentration decreased more slowly before rising rapidly after 250 hours of exposure. These trends are the result of the net reaction between YbMS and the CMAS composition utilized here, which, omitting oxygen, can be written as:

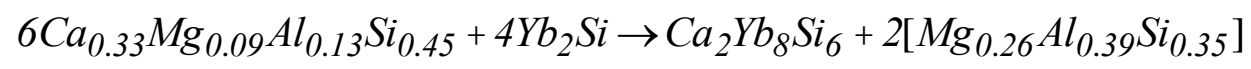

where the term in brackets represents the oxides not involved in the reaction and therefore rejected back into the melt. The formation of a molecular unit of apatite required the provision of two $\mathrm{Ca}^{2+}$ ions and two $\left(\mathrm{SiO}_{4}\right)^{4-}$ anions from the melt, with the other four $\left(\mathrm{SiO}_{4}\right)^{4-}$ anions supplied by the YbMS. Because the Ca:Si ration was $<1$, one can readily show that the removal of an equal number of moles of $\mathrm{CaO}$ and $\mathrm{SiO}_{2}$ from the melt would lead to a faster reduction in the of $\mathrm{CaO}$ concentration than that of $\mathrm{SiO}_{2}$. While this is in qualitative agreement with the data of Table 2, it cannot account for the nearly constant $\mathrm{SiO}_{2}$ concentration. One might further argue that because the total volume of melt is being reduced, some of the $\mathrm{Yb}^{3+}$ originally dissolved to saturate the melt would have to reprecipitate as apatite with the concomitant amounts of $\mathrm{Ca}$ and $\mathrm{Si}$, but that would result in slightly larger changes in the $\mathrm{CaO}$ and $\mathrm{SiO}_{2}$ concentrations. Moreover, the reaction of the $\sim 15$ vol.\% $\mathrm{Yb}_{2} \mathrm{O}_{3}$ second phase to form apatite should have consumed $\mathrm{Si}$ at a relatively faster rate than $\mathrm{Ca}$, as shown by the following reaction:

$$
13.33 \mathrm{Ca}_{0.33} \mathrm{Mg}_{0.09} \mathrm{Al}_{0.13} \mathrm{Si}_{0.45}+8 \mathrm{Yb} \rightarrow \mathrm{Ca}_{2} \mathrm{Yb}_{8} \mathrm{Si}_{6}+5.33\left[\mathrm{Ca}_{0.45} \mathrm{Mg}_{0.23} \mathrm{Al}_{0.32}\right]
$$


This would produce an increase in the $\mathrm{Ca}$ content and a substantial decrease in $\mathrm{SiO}_{2}$, again inconsistent with the nearly constant concentration of the latter observed in the CMAS over time. Moreover, reaction (1) also shows that the concentrations of $\mathrm{Mg}$ and $\mathrm{Al}$ should increase over time, which is in agreement with the trend for $\mathrm{Al}$ but not for $\mathrm{Mg}$. One possible explanation for these trends is that the melt began to gain access to the mullite underlayer at locally thinner regions the YbMS top coat. The ensuing dissolution then contributes only $\mathrm{SiO}_{2}$ and $\mathrm{AlO}_{1.5}$ to the melt, compensating for the consumption of $\mathrm{SiO}_{2}$ to form apatite and raising the $\mathrm{Al}$ concentration. Indeed, after the longest time, the reaction was seen to have locally consumed the entire YbMS layer and CMAS had become in contact with the mullite and even the Si underlayers, Figure 11(a), consistent with the noticeable increases in the $\mathrm{SiO}_{2}$ and $\mathrm{AlO}_{1.5}$ between $100 \mathrm{~h}$ and $200 \mathrm{~h}$, Table 2. In principle, CMAS might also reach the mullite layer via penetration through YbMS channel cracks. However, there was no visual evidence of significant penetration by this mechanism for these isothermal (non-cyclic) tests.

The thickness of the equivalent reaction layer (after subtracting the entrained glass phase) exhibited a power law time dependence with an exponent that evolved from $\sim 1 / 4$ during the early exposure to $\sim 1 / 2$ after longer exposure times, Figure 6 . This is consistent with the hypothesis that the overall volume of apatite was growing at a rate controlled by diffusion of $\mathrm{Ca}$ and $\mathrm{Si}$ through the thin amorphous films at the apatite grain boundaries shown in Figure 9. The reaction layer, however, evolves in structure to incorporate increasing amounts of the glassy phase above the dense layer of columnar apatite crystals. The evidence in Figure 6 reveals that the thickness of the dense reaction layer increases with a power law exponent $n \sim 1 / 4$ over the entire exposure time period examined, which suggests the effective diffusion coefficient is decreasing over time. This is ascribed to the increase in the apatite crystal width over time shown in Figure 8 and in quantitative form in Figure 10. The implication is that the number of grain boundaries per unit area is decreasing with the layer thickness, which would decrease the effective diffusion coefficient and the rate constant, in agreement with the evidence. A similar effect has been observed in the growth of alumina scales on metallic substrates, which is also controlled by grain boundary diffusion [28]. It therefore appears that both diffusion kinetics and arguably the progressive depletion of $\mathrm{Ca}$ from the CMAS contributed to the gradual slowing of the reaction with time. 
The YbDS coatings also initially reacted rapidly with molten CMAS at $1300^{\circ} \mathrm{C}$ to form apatite of very similar composition as that for YbMS, Table 3, albeit with a coarser morphology and without an evident dense layer at the interface, Figure 14. Indeed, there was no well-defined near-planar reaction front formed on the YbDS coatings as seen for YbMS in Figure 8. The reaction of CMAS with YbDS to form apatite reaction product can occur without any contribution of Si from the melt, as shown by the following reaction:

$$
{ }_{6 C a_{0.33}} \mathrm{Mg}_{0.09} \mathrm{Al}_{0.13} \mathrm{Si}_{0.45}+4 \mathrm{Yb}_{2} \mathrm{Si}_{2} \rightarrow \mathrm{Ca}_{2} \mathrm{Yb}_{8} \mathrm{Si}_{6}+6\left[\mathrm{Mg}_{0.09} \mathrm{Al}_{0.13} \mathrm{Si}_{0.78}\right]
$$

The reaction now involves a net release of $\mathrm{SiO}_{2}$ from the YbDS into the CMAS melt, as shown by comparing the Si content of the original CMAS and the residue, with an increase in the amount of residue added to the melt relative to reaction (1). The inference is that $\mathrm{Ca}^{2+}$ must still be diffusively transported to the reaction front through the glassy phase, but there is no need for drawing $\mathrm{SiO}_{2}$ from the melt to form apatite. Instead, the excess $\mathrm{SiO}_{2}$ released would have to be transported outward toward the bulk melt through the network of glassy channels in the reaction layer. The scenario is consistent with the depletion in $\mathrm{Ca}$ over time in Table 4, but again at variance with an apparently constant $\mathrm{SiO}_{2}$ concentration in the bulk melt. One may hypothesize that some of the excess $\mathrm{SiO}_{2}$ released by the reaction could be used to feed the reaction with the YbMS second phase according to reaction (1), reducing the need for net exchange of $\mathrm{SiO}_{2}$ with the bulk melt. The Si contents listed in Table 5, however, are significantly higher than expected from the initial dissolution of YbDS to saturate the melt.

A salient finding of this work is that the CMAS reaction with YbDS progressed by a different mechanism to that between CMAS and YbMS, as schematically illustrated in Figure 15(b). The molten CMAS preferentially reacted with regions containing a high fraction of YbMS segregates as noted in Figure 1(b) and (d). This resulted in the deep intrusion of the reaction front into the topcoat and left the YbDS regions of the coating to react more slowly. The mechanism of reaction was influenced by the presence of YbMS as a second phase within YbDS, as well as by the as-deposited coating morphology.

Notwithstanding the differences in mechanism, the results in Figure 6 suggest that the evolution of the reaction layer on YbDS follows a similar power law time dependence but with a slightly smaller rate constant than that of YbMS. The rationale is that the process is still 
controlled by diffusion through the glass network, but the increase in diffusional area is counteracted by the enrichment in $\mathrm{SiO}_{2}$ of the region between the growing apatite grains and the dissolving YbDS/YbMS coating.

The YbDS coatings were eventually breached locally by dissolution into CMAS after exposure at $1300^{\circ} \mathrm{C}$ for $250 \mathrm{~h}$, Figure $11(\mathrm{~b})$, as were those for YbMS, Figure 11(a). This occurred at locally thinner $(\sim 40-50 \mu \mathrm{m}$ thick) regions of the YbDS coating whose thickness was sometimes similar to the equivalent reaction layer thickness after exposure for $250 \mathrm{~h}$. Once penetration reached the mullite layer, the local enrichment in Al promoted the formation of anorthite $\left(\mathrm{CaAl}_{2} \mathrm{Si}_{2} \mathrm{O}_{8}\right)$ platelets, Figure 14(a). The dissolution rate apparently increased enabling the melt to reach the bond coat. Further attack is likely to involve oxidation of the Si bond coat by diffusion of oxygen through the local CMAS pool and its subsequent dissolution into the CMAS, with potential for eventually reaching the $\mathrm{SiC}$ substrate. The consequences of subsequent oxidation of the $\mathrm{SiC}$ are better represented in Figure 11(a), where a large bubble resulted from the evolution of $\mathrm{CO}$ during the reaction.

\section{Conclusions}

It has been shown that molten CMAS poses a serious threat to the durability of EBC systems based on $\mathrm{Yb}$ silicates. Both YbMS and YbDS were dissolved by molten CMAS and precipitated the same apatite phase. The overarching mechanism was dissolution of the silicate and reprecipitation as apatite, with some important differences in reaction morphology between YbMS and YbDS. The net thickness of reaction product followed a power law dependence on time for both coatings, with an exponent of $\sim 1 / 4$ at shorter times that evolves toward $\sim 1 / 2$ as the time increased. In both cases, the reaction was arguably controlled by diffusion of $\mathrm{Ca}$ and $\mathrm{Si}$ through the glass network interpenetrating the apatite product close to the dissolving silicate. However, the reaction front with YbMS involved a nearly dense layer of columnar apatite crystals with thin amorphous films at the grain boundaries, which is consistent with a rate controlled by diffusion through the grain boundaries of this dense layer. The change in power law exponent is attributed to coarsening of the apatite grains with an accompanying reduction in the density of grain boundaries per unit area of the advancing interface. The reaction scenario for YbDS was less clear because no dense layer develops. The reaction involves inward diffusion of $\mathrm{Ca}$ from the bulk melt in both cases, but whereas YbMS requires inward diffusion of 
Si to form apatite, YbDS rejects Si during the reaction, and this must be diffused outward. It is hypothesized that the accumulation of $\mathrm{Si}$ at the dissolution front reduces the rate of diffusional transport through it, even if the area fraction of fast diffusion paths may be greater.

The presence of $\mathrm{Yb}_{2} \mathrm{O}_{3}$ as a minor phase within the $\mathrm{YbMS}$ top coat appears to have less influence on the reaction process than the presence of YbMS dispersed within the YbDS layer. The latter seems to provide a preferential path for penetration of the CMAS through reaction with the YbMS, presumably because of the $\mathrm{SiO}_{2}$ enriched glass around the dissolving $\mathrm{YbDS}$ grains. It is clear that in situations where the reaction rate is not controlled by the availability of silicate deposits, the reaction between CMAS and tri-layer EBC's with nominally $100 \mu \mathrm{m}$ thick YbMS or YbDS top coats is sufficiently aggressive at $1300^{\circ} \mathrm{C}$ to seriously imperil the desired 5,000 to 10,000 hour operational life of $\mathrm{SiC}$ composite components.

\section{Acknowledgments}

The assistance of Dr. Christopher Winkler and James Tuggle with the TEM work at Virginia Tech is greatly appreciated. Three of the authors (BTR, HZ and HNGW) are grateful to the Office of Naval Research for supporting the research under contract N00014-03-1-0297 monitored by Dr. David Shifler. Support for CGL was provided by ONR grant N00014-14-10625, also monitored by Dr. Shifler. 
References:

[1] K.N. Lee, Surface and Coatings Technology, 133-134 (2000) 1-7.

[2] M. Belmonte, Advanced Engineering Materials, 8 (2006) 693-703.

[3] N.S. Jacobson, Journal of the American Ceramic Society, 76 (1993) 3-28.

[4] T. Narushima, T. Goto, T. Hirai, Y. Iguchi, Materials Transactions, JIM, 38 (1997) 821-835.

[5] E.J. Opila, J.L. Smialek, R.C. Robinson, D.S. Fox, N.S. Jacobson, Journal of the American Ceramic Society, 82 (1999) 1826-1834.

[6] E.J. Opila, Journal of the American Ceramic Society, 86 (2003) 1238-1248.

[7] I. Spitsberg, J. Steibel, International Journal of Applied Ceramic Technology, 1 (2004) 291-301.

[8] M. van Roode, J.R. Price, C. Stala, Journal of Engineering for Gas Turbines and Power, 115 (1993) 139147.

[9] N.S. Jacobson, D.S. Fox, J.L. Smialek, C. Deliacorte, K.N. Lee, in: GRC (Ed.), NASA Glenn Research Center, Cleveland, OH, USA, 2005.

[10] B.T. Richards, H. Zhao, H.N.G. Wadley, Journal of Materials Science, 50 (2015) 7939-7957.

[11] K.N. Lee, Protective coatings for gas turbines, National Energy Technology Laboratory (NETL), 2006.

[12] K.M. Grant, S. Krämer, G.G.E. Seward, C.G. Levi, Journal of the American Ceramic Society, 93 (2010) 3504-3511.

[13] N.L. Ahlborg, D. Zhu, Surface and Coatings Technology, 237 (2013) 79-87.

[14] J.M. Drexler, A.L. Ortiz, N.P. Padture, Acta Materialia, 60 (2012) 5437-5447.

[15] S. Krämer, J. Yang, C.G. Levi, C.A. Johnson, Journal of the American Ceramic Society, 89 (2006) 31673175.

[16] H. Zhao, C.G. Levi, H.N.G. Wadley, Surface and Coatings Technology, 251 (2014) 74-86.

[17] C.G. Levi, J.W. Hutchinson, M.-H. Vidal-Sétif, C.A. Johnson, MRS Bulletin, 37 (2012) 932-941.

[18] K.M. Grant, S. Krämer, J.P.A. Löfvander, C.G. Levi, Surface and Coatings Technology, 202 (2007) 653657.

[19] E.M. Zaleski, C. Ensslen, C.G. Levi, Journal of the American Ceramic Society, 98 (2015) 1642-1649.

[20] B.T. Richards, H.N.G. Wadley, Journal of the European Ceramic Society, 34 (2014) 3069-3083.

[21] B.T. Richards, M.R. Begley, H.N.G. Wadley, Journal of American Ceramic Society, p. 1-10, 2015

[22] K.N. Lee, D.S. Fox, N.P. Bansal, Corrosion of Ceramic Matrix Composites, 25 (2005) 1705-1715.

[23] D.L. Poerschke, D.D. Hass, S. Eustis, G.G.E. Seward, J.S. Van Sluytman, C.G. Levi, Journal of the American Ceramic Society, 98 (2015) 278-286.

[24] H. Chen, Y. Gao, Y. Liu, H. Luo, Inorganic Chemistry, 49 (2010) 1942-1946.

[25] B.T. Richards, K.A. Young, F Francquville, S. Sehr, M.R. Begley, H.N.G. Wadley, Acta Materialia, Submitted, (2015).

[26] N.F. Fedorov, I.F. Andreev, N.S. Meliksetyan, Inorganic Materials,11 (1975) 1137-1138.

[27] S. Krämer, J. Yang, C.G. Levi, Journal of the American Ceramic Society, 91 (2008) 576-583.

[28] W.J. Quadakkers, D. Naumenko, E. Wessel, V. Kochubey, L. Singheiser, Oxidation of Metals, 61 (2004) 17-37. 

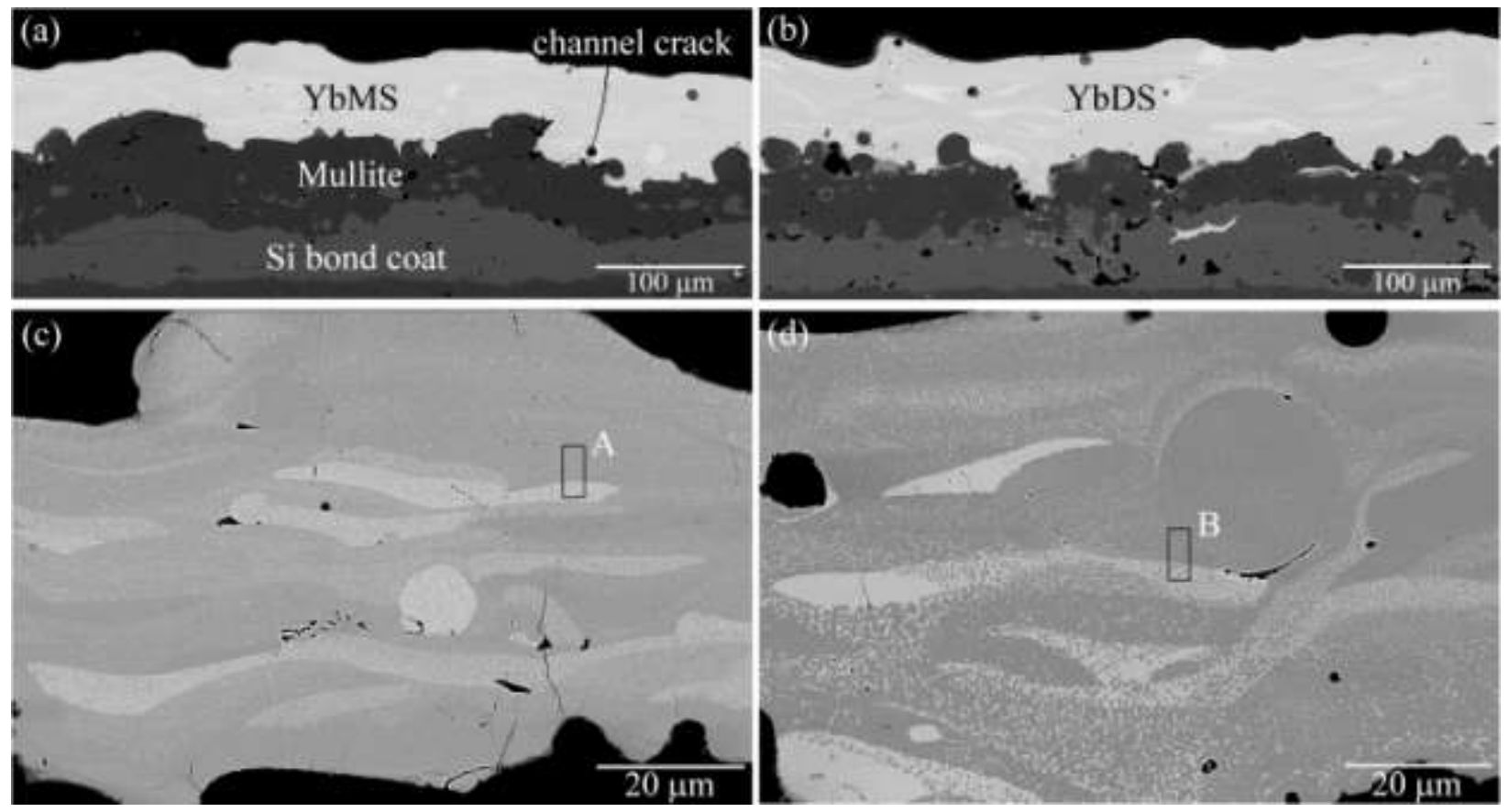

Figure 1. SEM images (in BSE mode) of annealed tri-layer coatings with (a) ytterbium monosilicate and (b) ytterbium disilicate top coats. The structure of the ytterbium monosilicate layer is shown in (c) and that of the ytterbium disilicate layer in (d). The green box regions identified as A and B mark positions where FIB lift-out lamellae were extracted for subsequent transmission electron microscopy. 


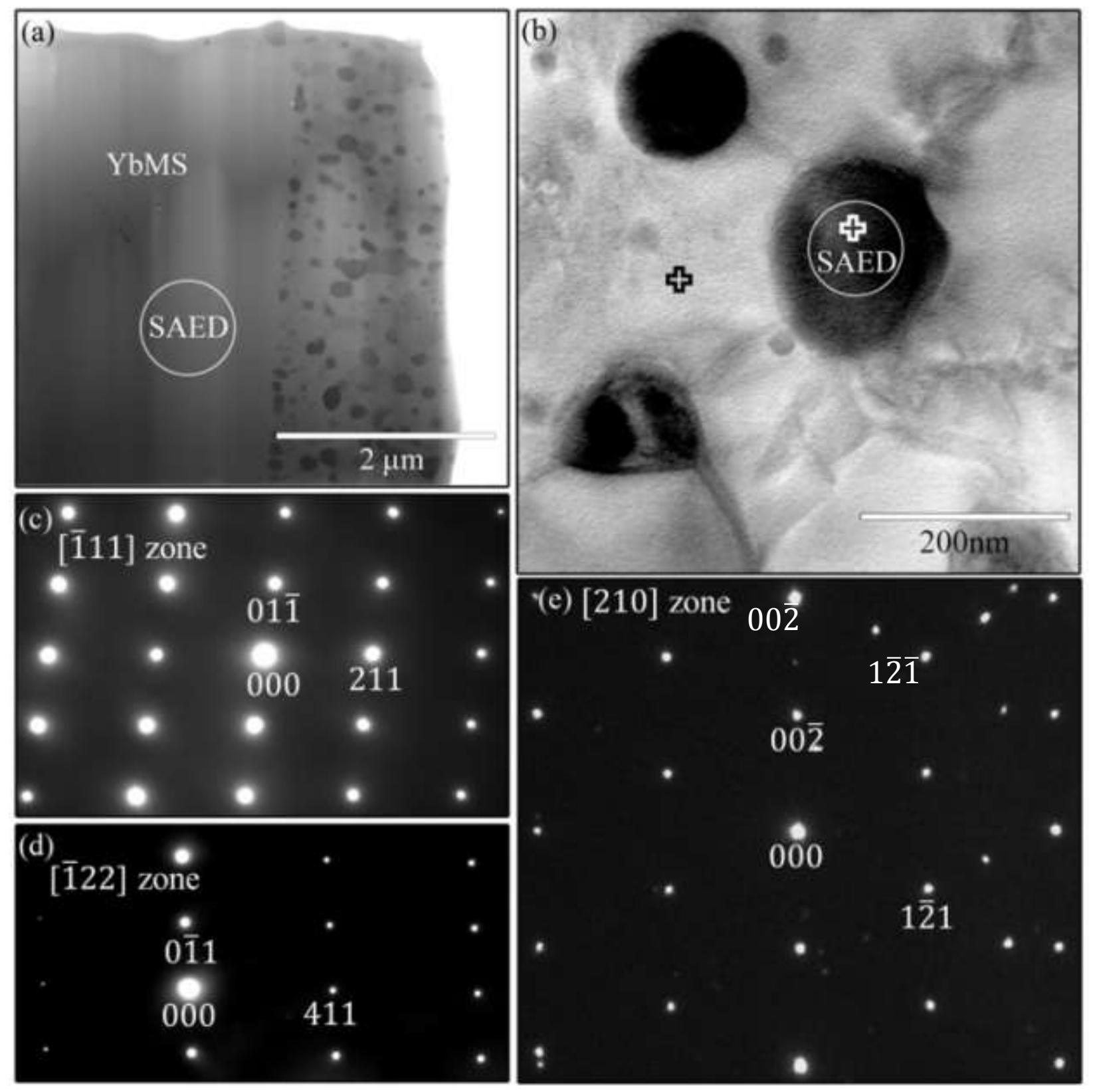

Figure 2. (a) Bright field TEM image of an annealed YbMS coating (area A shown in Figure 1) and (b) image of particles taken at high magnification. The SAED patterns of the monoclinic YbMS matrix for the region shown in (a) along the [011], and [155] zone axes are shown in (c) and (d). (e) Shows the SAED pattern of a cubic $\mathrm{Yb}_{2} \mathrm{O}_{3}$ particle along its [210] zone axis. 


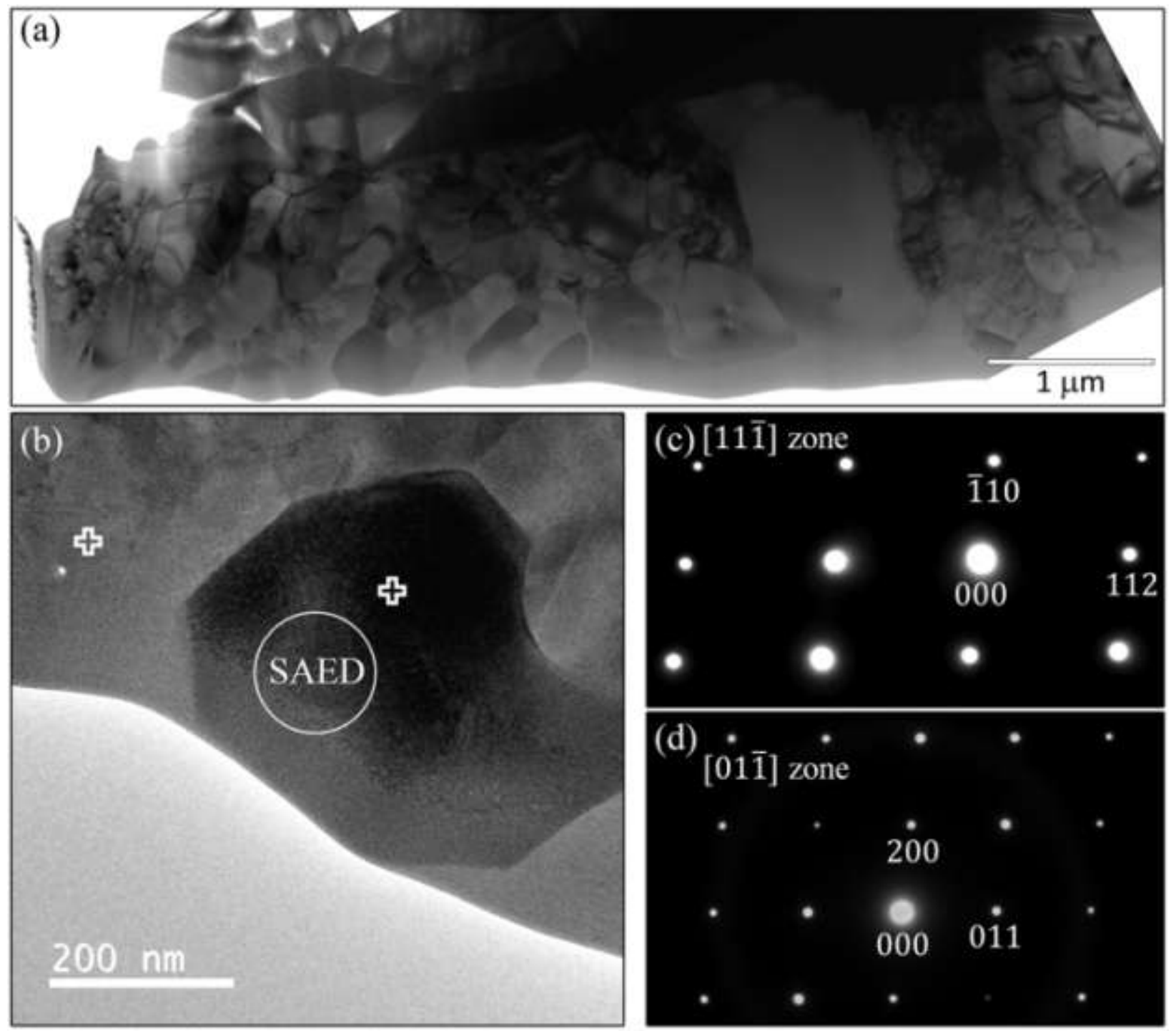

Figure 3. (a) Bright field TEM image of the annealed YbDS coating (area B in Figure 2) and (b) segregated YbMS particle in the disilicate coating showing the region where SAED was

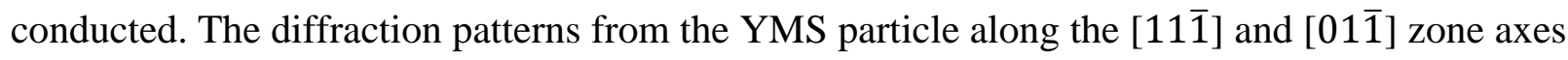
are shown in (c) and (d) respectively. 

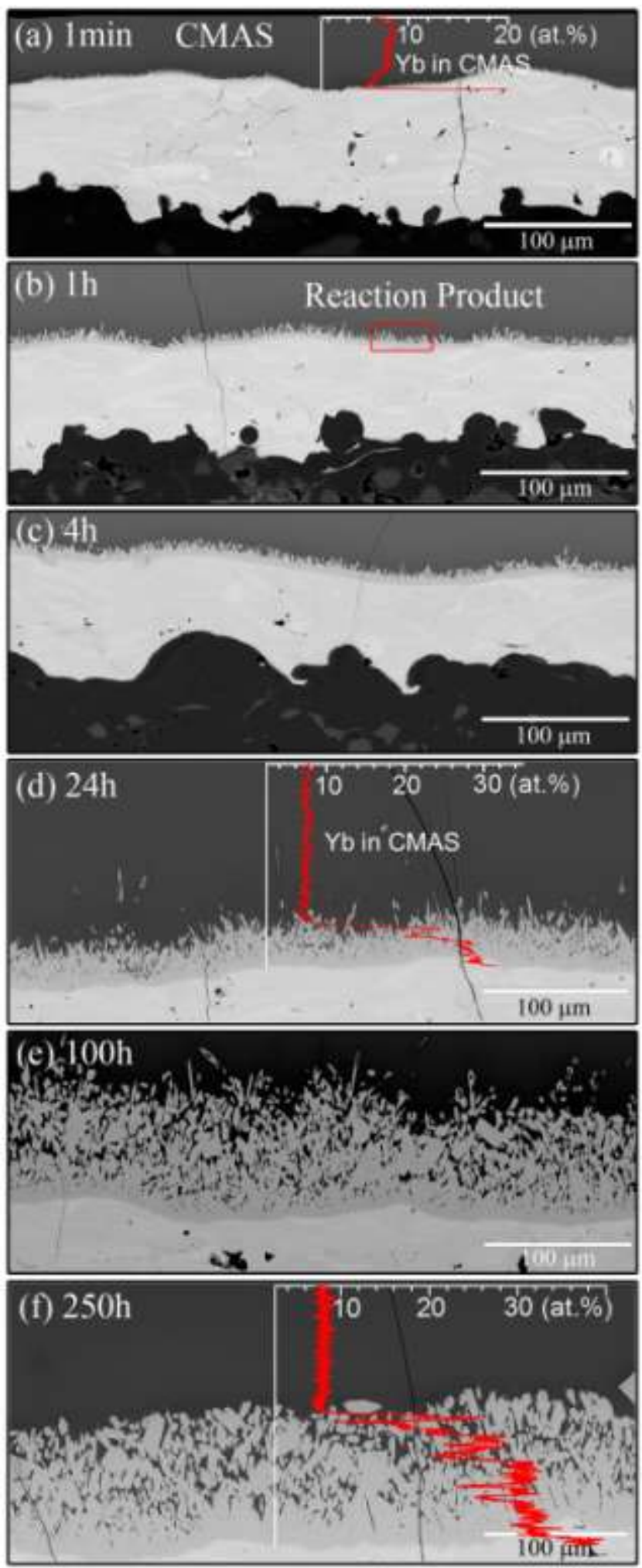

Figure 4. SEM images showing the formation of a reaction layer during YbMS coating exposure to CMAS at $1300{ }^{\circ} \mathrm{C}$ for (a) $1 \mathrm{~min}$, (b) $1 \mathrm{~h}$, (c) $4 \mathrm{~h}$, (d) $24 \mathrm{~h}$, (e) $100 \mathrm{~h}$ and (f) $250 \mathrm{~h}$. 

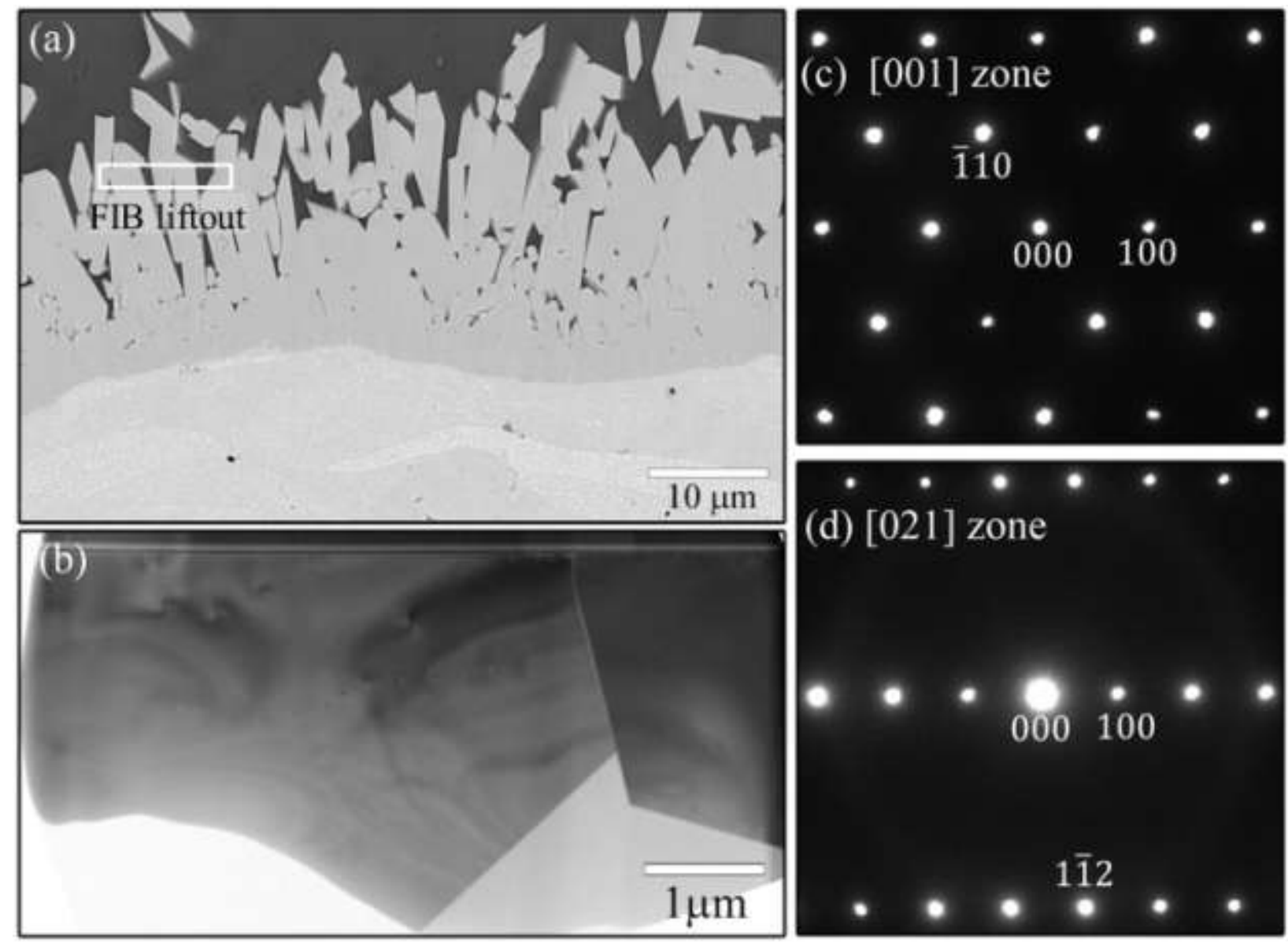

Figure 5. (a) A SEM image of the reaction zone of a YbMS coating after a $24 \mathrm{~h}$ exposure to CMAS at $1300{ }^{\circ} \mathrm{C}$. The white box marks the position where a FIB lamella was extracted for transmission electron microscopy. (b) Shows a bright field TEM image of the reaction product from the location indicated in (a). The SAED patterns along (c) the [001] and (d) the [021] zone axes from the region shown in (b) are consistent with those of an apatite phase particle. 


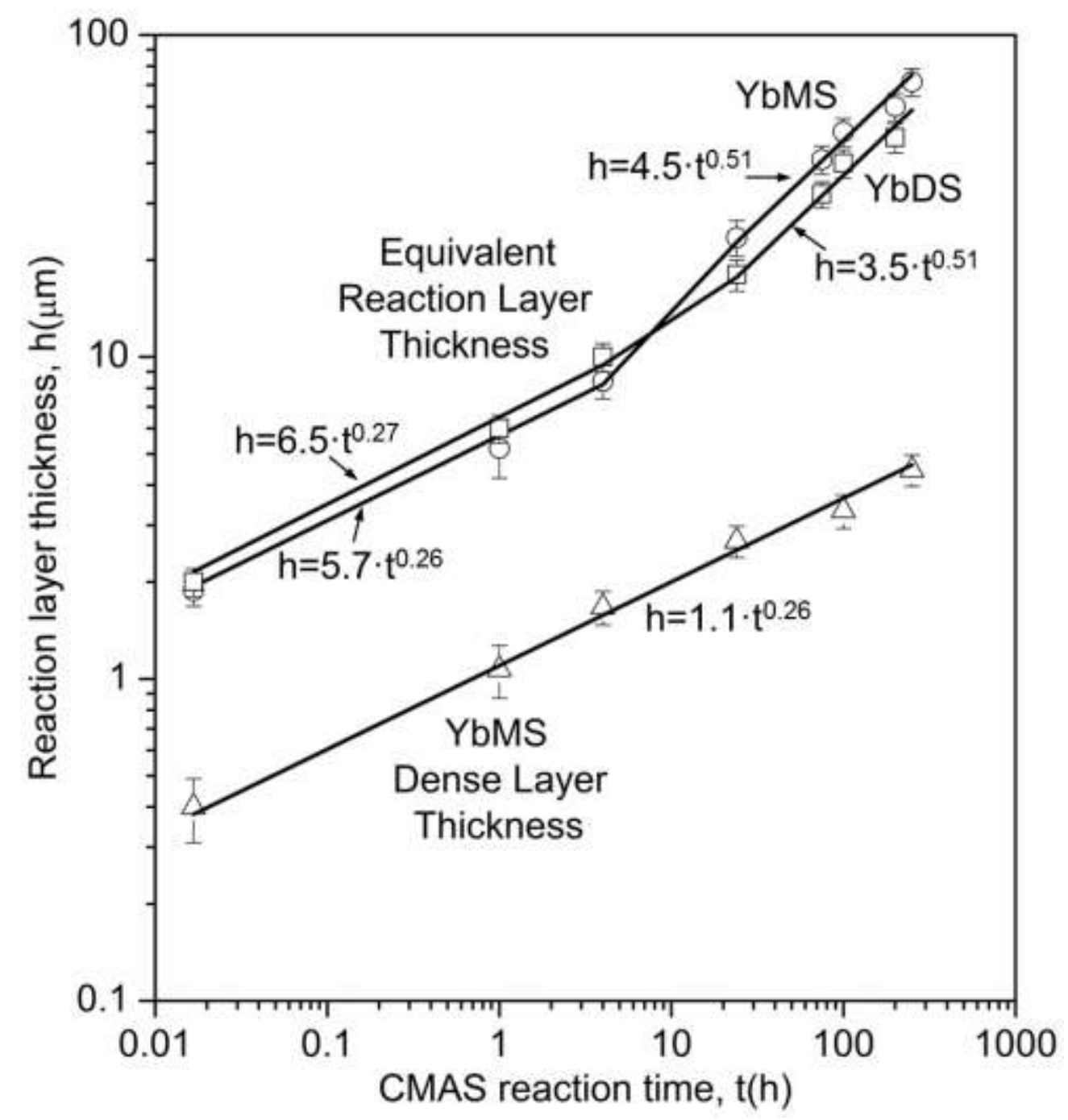

Figure 6. The equivalent reaction layer thickness plotted as a function of reaction time at $1300{ }^{\circ} \mathrm{C}$ for both ytterbium monosilicate and disilicate coatings under the assumption that the reaction layer is densely packed. 


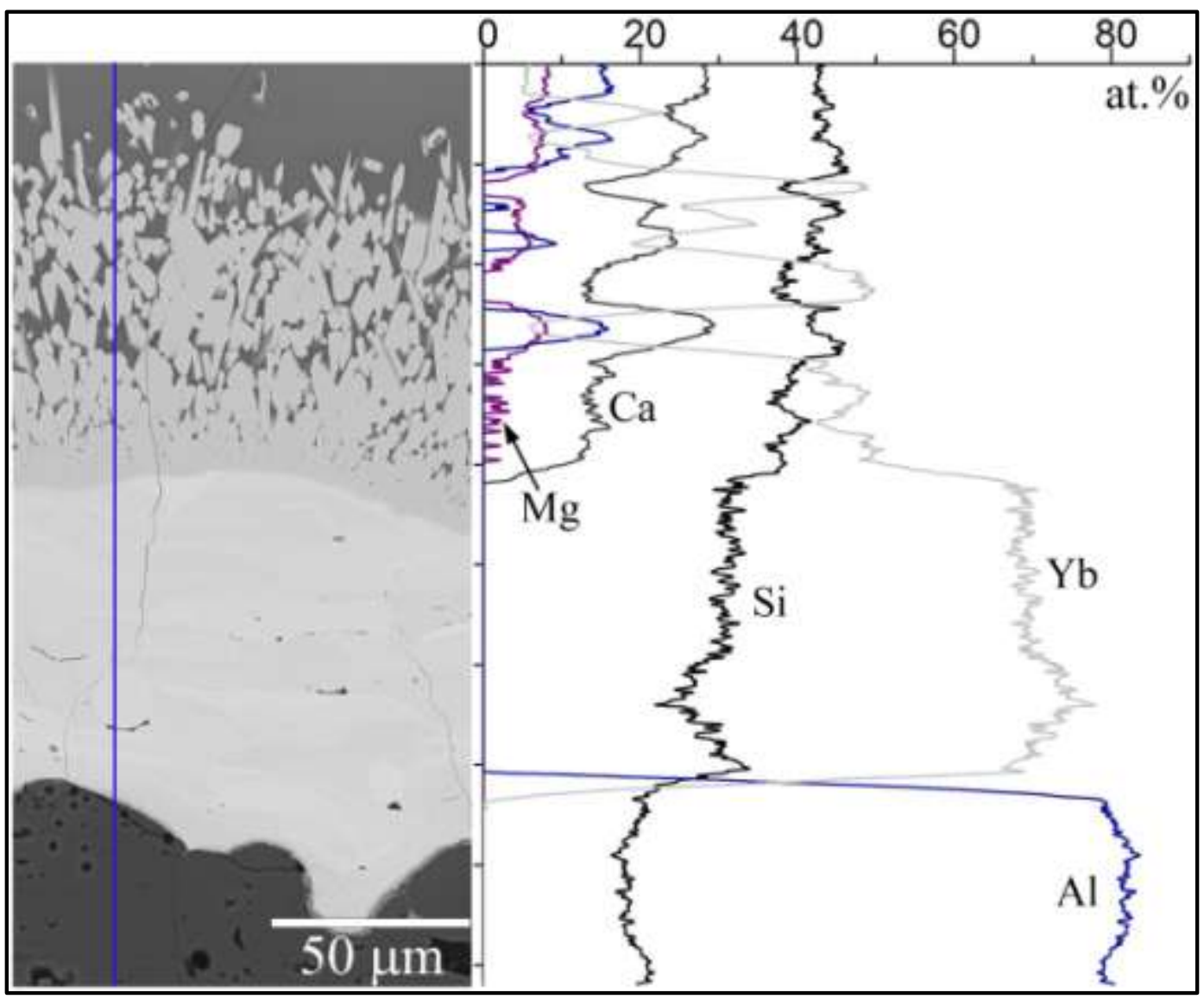

Figure 7. EDS composition profile analysis of the coating after exposure of YbMS to CMAS for $100 \mathrm{~h}$ at $1300{ }^{\circ} \mathrm{C}$. 


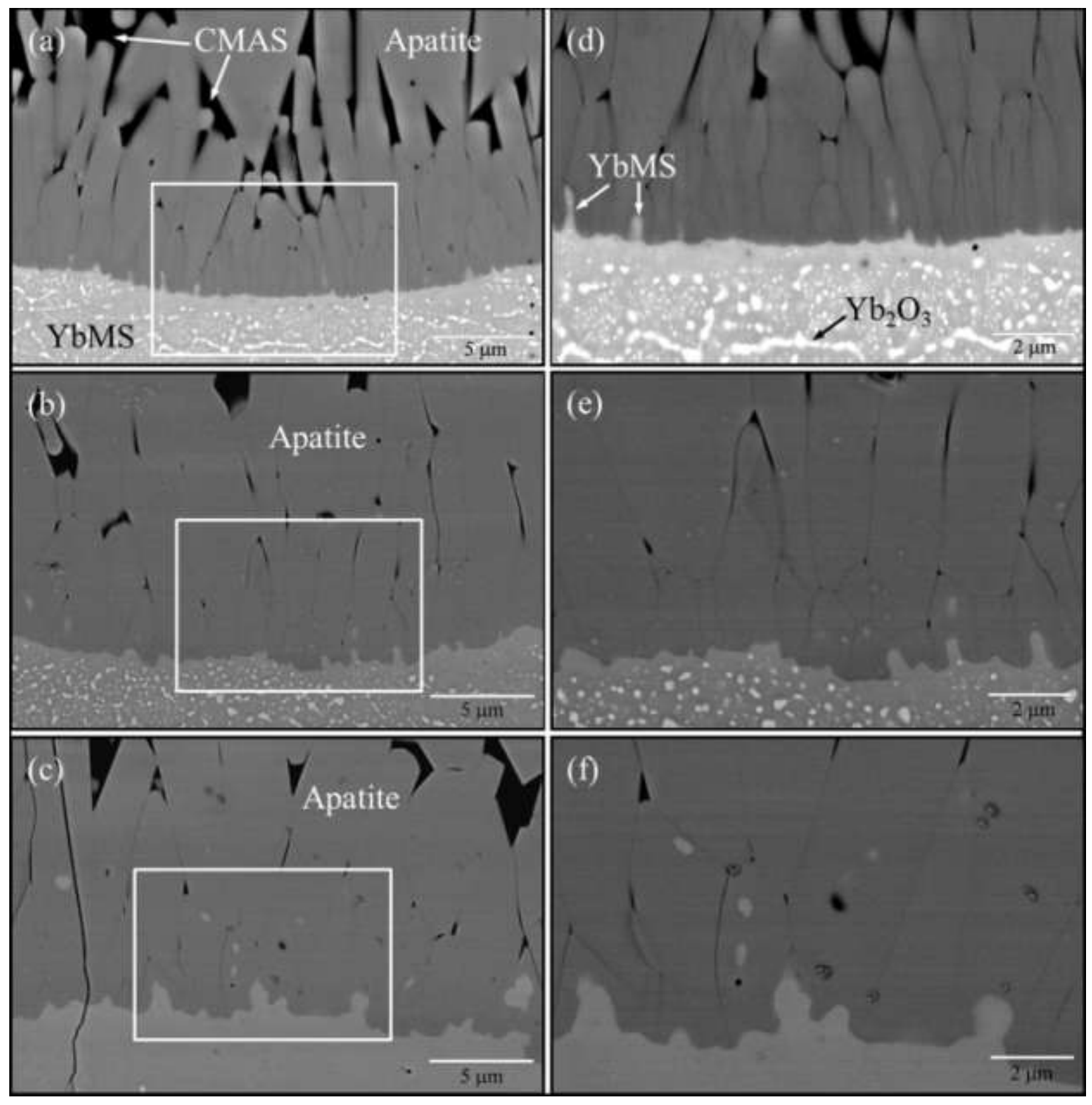

Figure 8. SEM images of cross sections normal to the ytterbium monosilicate/reaction product interface after reaction for $24 \mathrm{~h}(\mathrm{a}, \mathrm{c}), 100 \mathrm{~h}(\mathrm{~b}, \mathrm{e})$ and $250 \mathrm{~h}(\mathrm{c}, \mathrm{f})$ at $1300{ }^{\circ} \mathrm{C}$. 

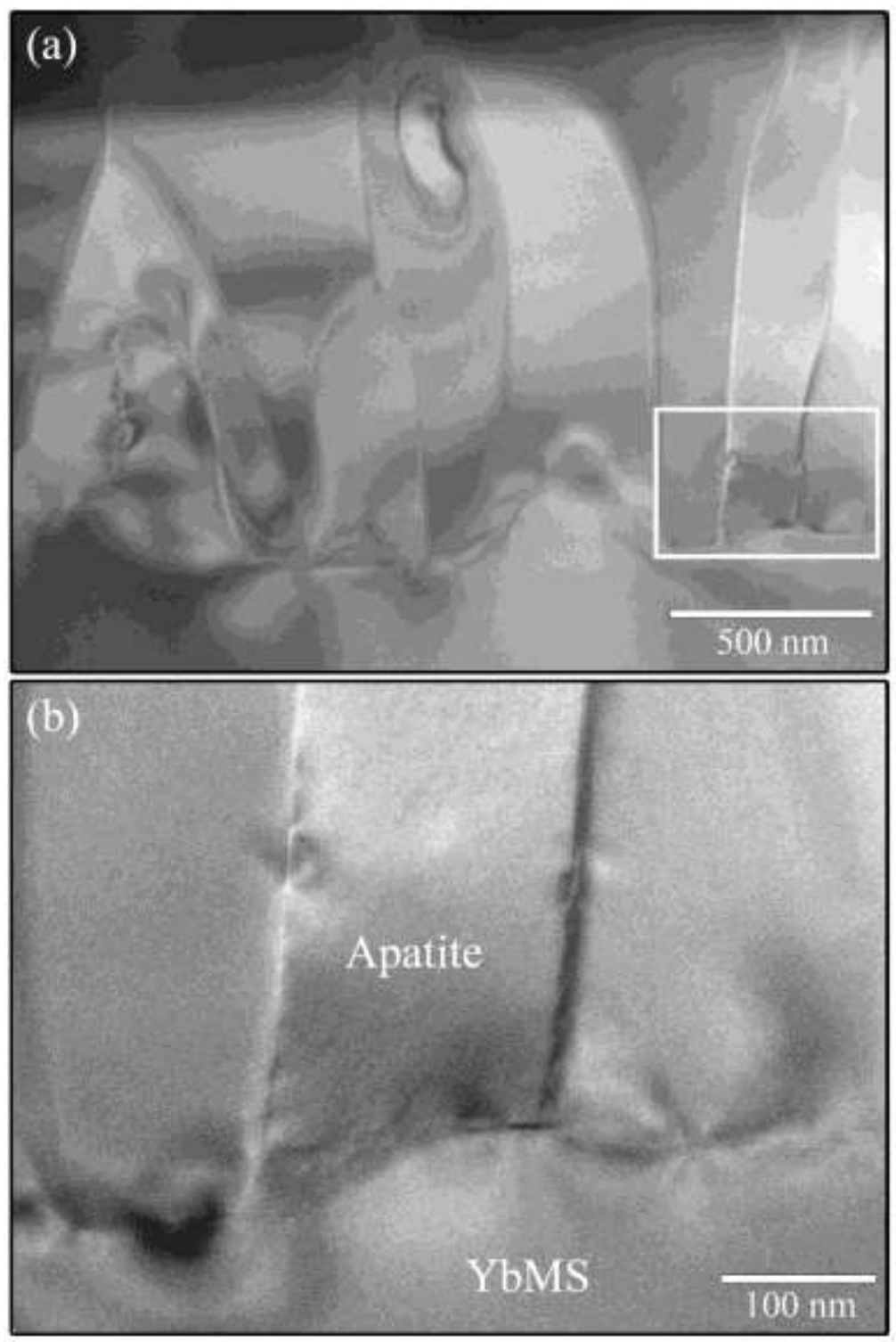

Figure 9. Bright field TEM images of cross sections normal to the ytterbium monosilicate/apatite interface after reaction for $24 \mathrm{~h}$ at $1300{ }^{\circ} \mathrm{C}$. 


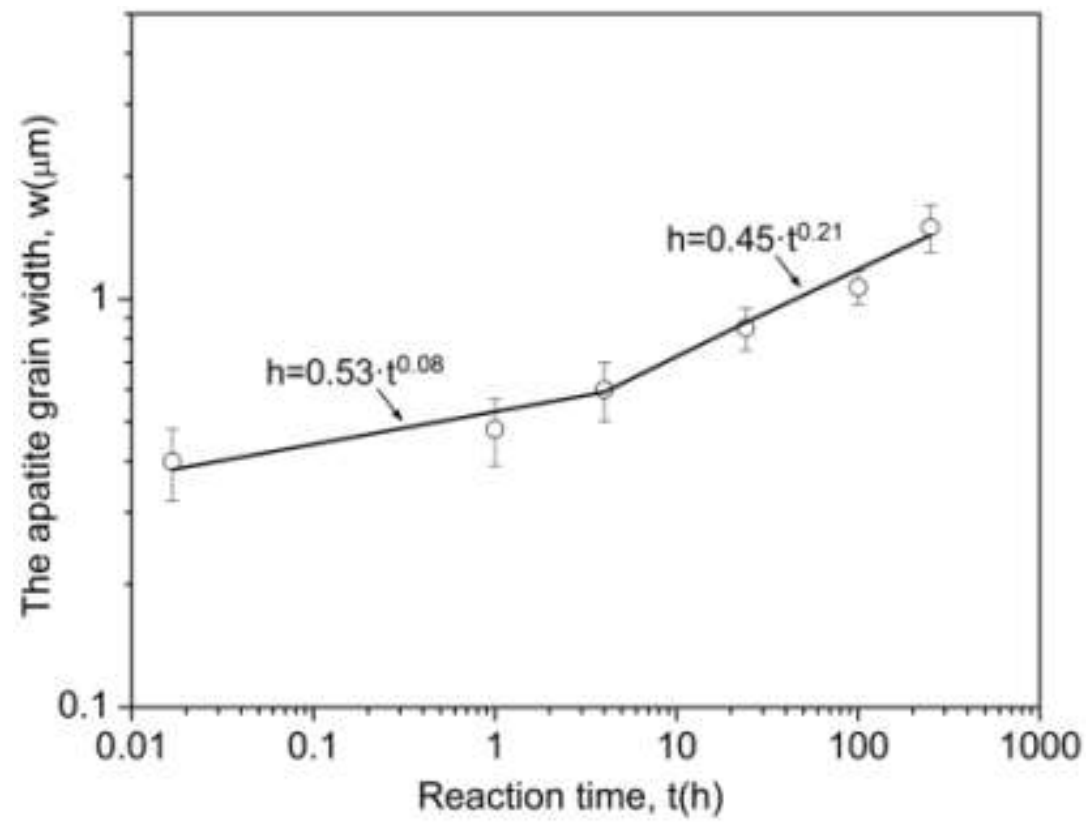

Figure 10. The apatite grain width at the interface of YbMS with the apatite layer is plotted as a function of the molten CMAS exposure time. 

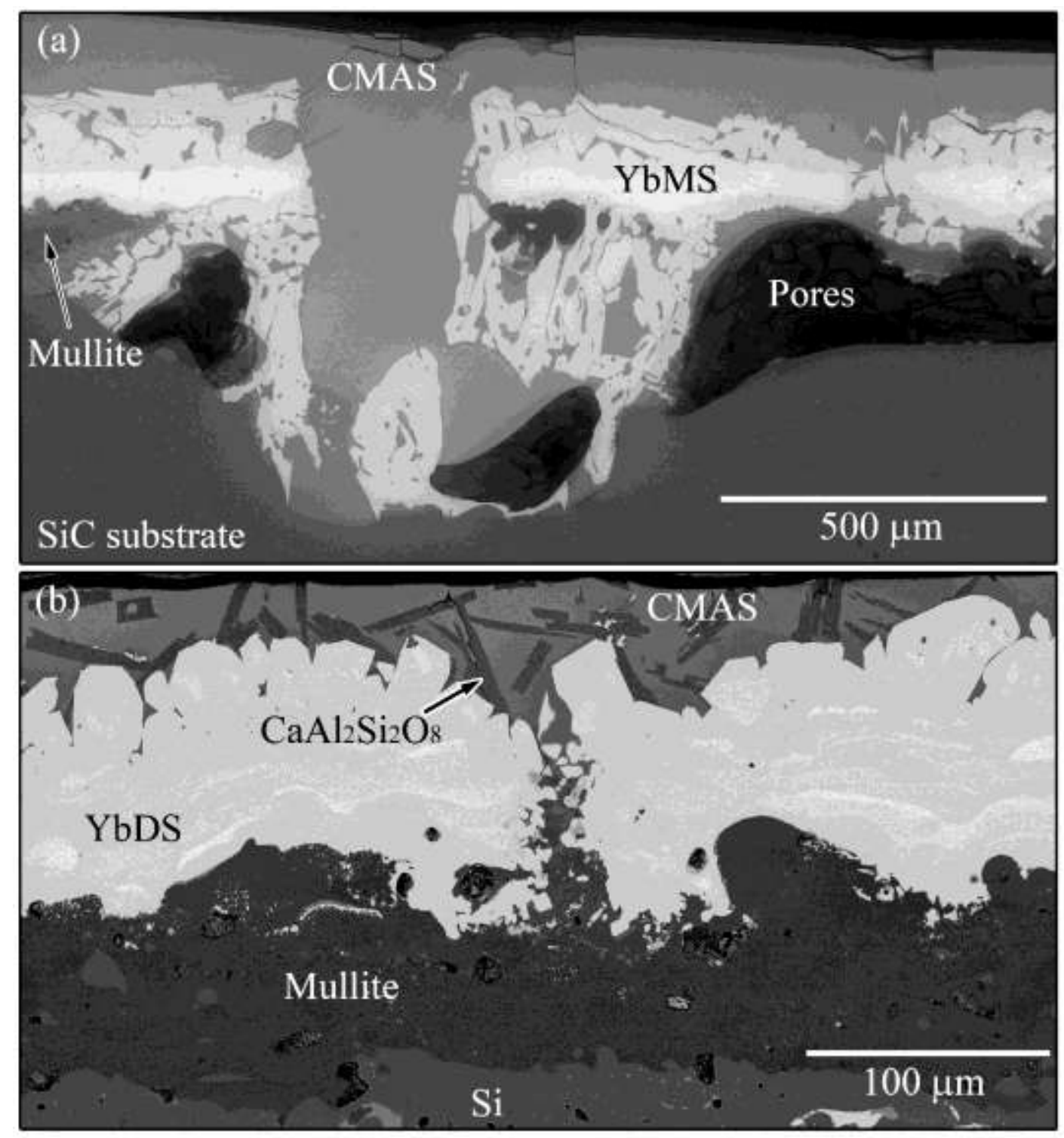

Figure 11. SEM BSE mode images of (a) YbMS and (b) YbDS tri-layer samples exposed to CMAS for $250 \mathrm{~h}$ at $1300{ }^{\circ} \mathrm{C}$ showing eventual penetration of the coatings by CMAS. Note the large pores in (a) and anorthite $\left(\mathrm{CaAl}_{2} \mathrm{Si}_{2} \mathrm{O}_{8}\right)$ platelets precipitated in the CMAS melt in (b). 

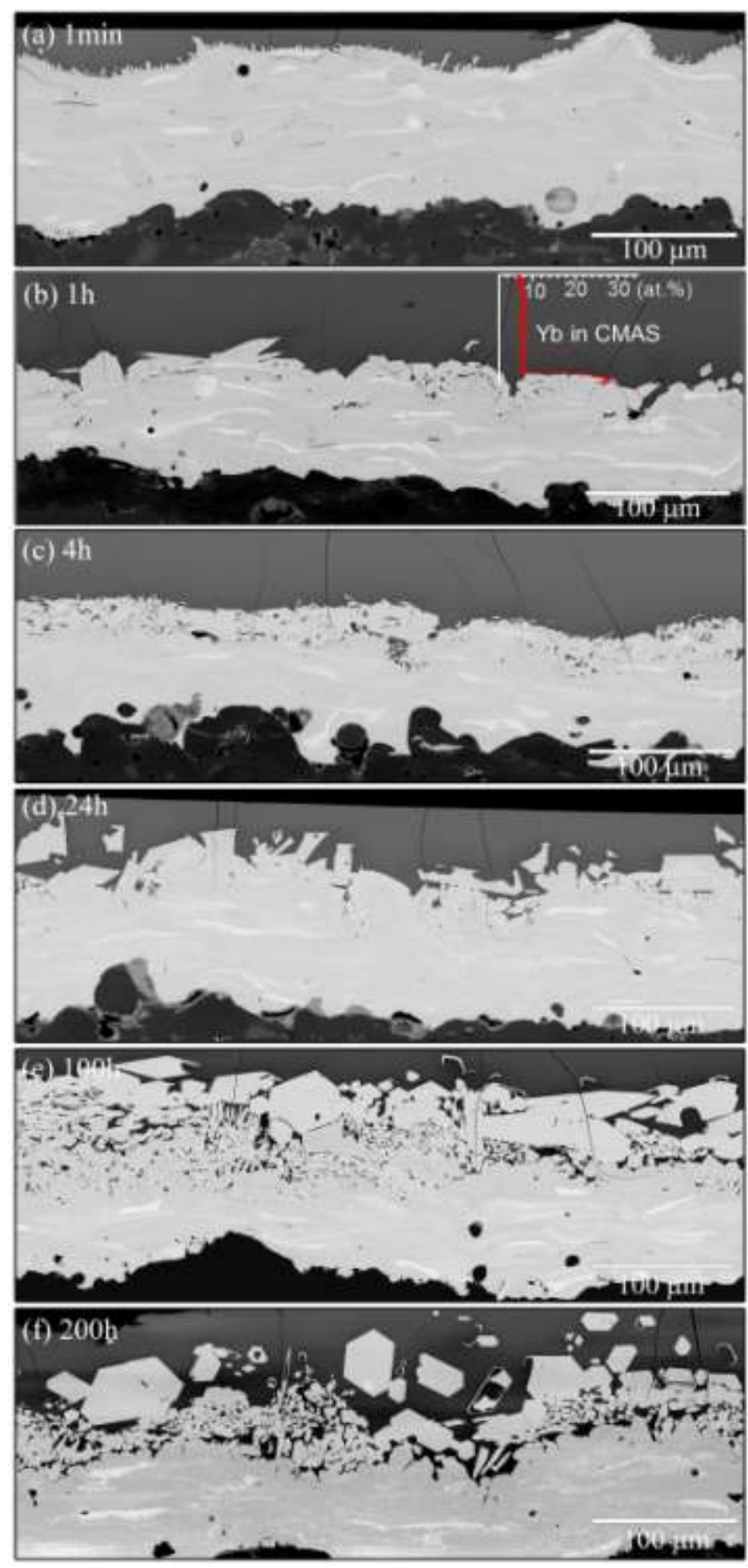

Figure 12. SEM images in BSE mode showing development of a reaction layer between YbDS and CMAS after reaction at $1300{ }^{\circ} \mathrm{C}$ for (a) less than $1 \mathrm{~min}$, (b) $1 \mathrm{~h}$, (c) $4 \mathrm{~h}$, (d) $24 \mathrm{~h}$, (e) $100 \mathrm{~h}$ and (f) $200 \mathrm{~h}$. The lighter contrast regions in the $\mathrm{YbDS}$ layer are solidified droplets with a lower silicon content and consisted of a mixture of $\mathrm{YbMS}$ and $\mathrm{Yb}_{2} \mathrm{O}_{3}$. 


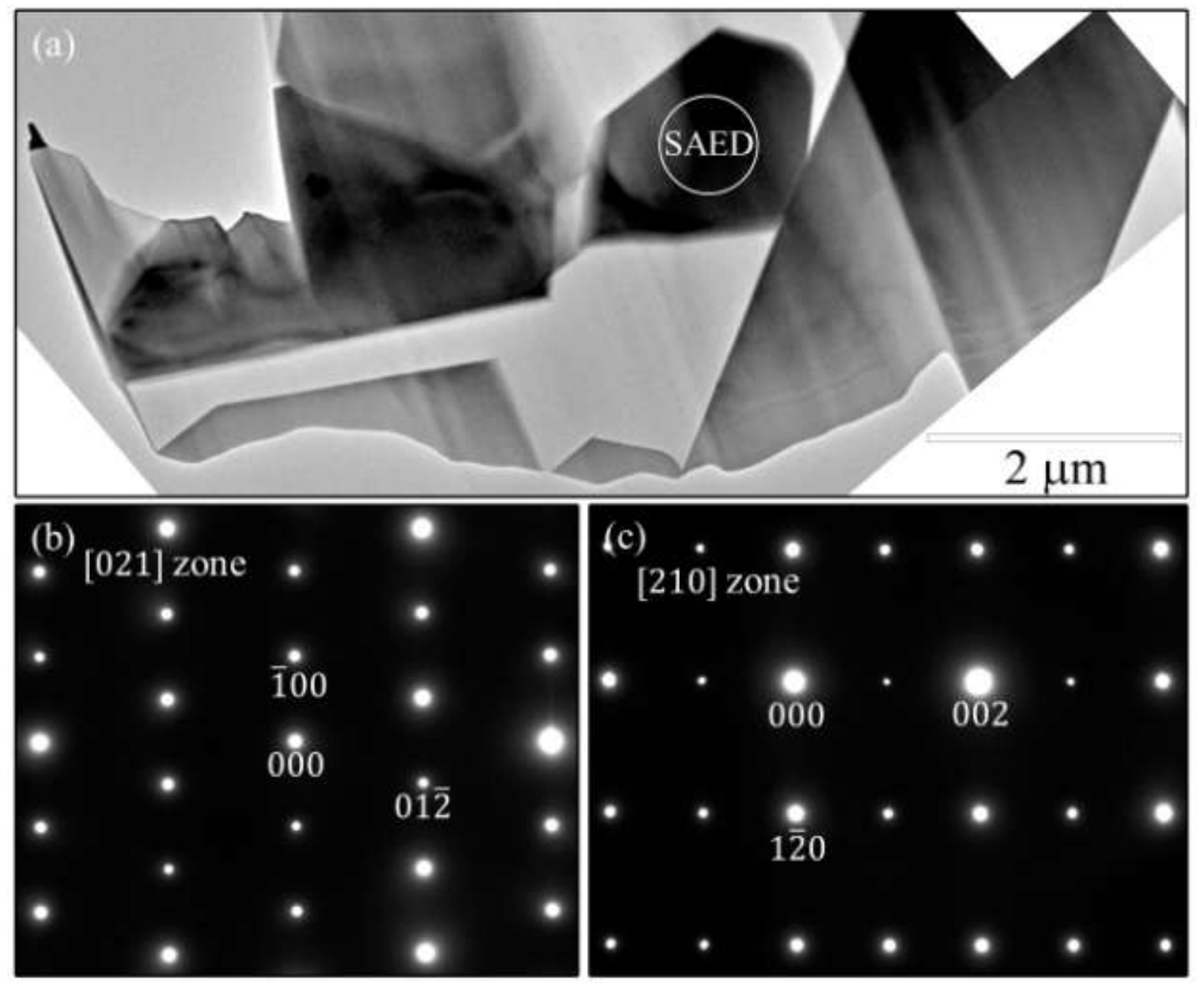

Figure 13. (a) Shows a bright field TEM image of the reaction product between YbDS and CMAS. TEM EDS analysis and the SAED patterns of the [021] (b) and [210] (c) zone axes from the reaction product particle are YbMS and CMAS. 

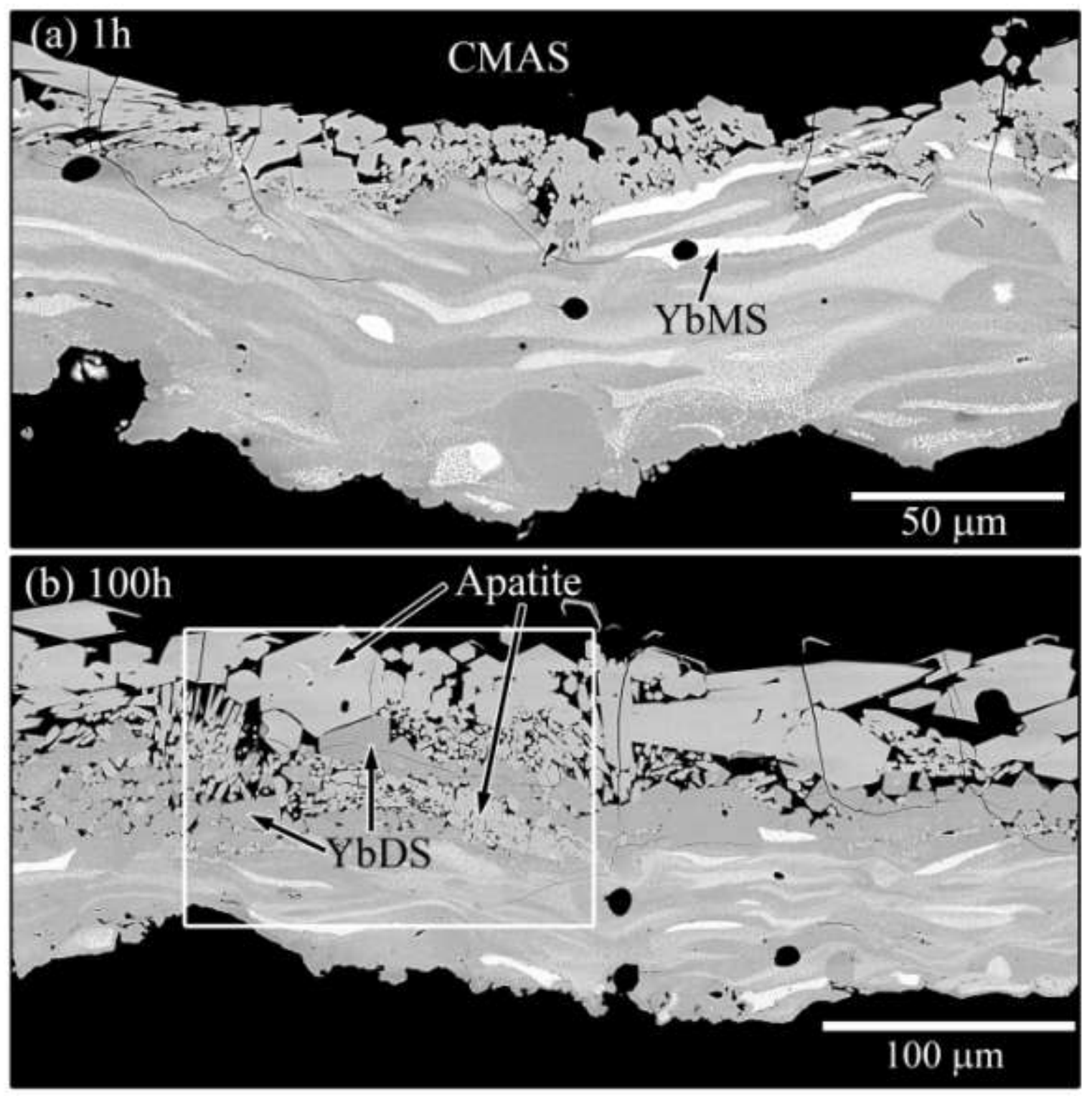

Figure 14. BSE image of the YbDS top coat after exposure to CMAS at $1300{ }^{\circ} \mathrm{C}$ for (a) $1 \mathrm{~h}$ and (b) $100 \mathrm{~h}$. Note that the apatite phases first penetrated the coating in $\mathrm{SiO}$ depleted (lighter contrast YbMS rich) regions and became inter mixed with unreacted YbDS particles in the coating. 

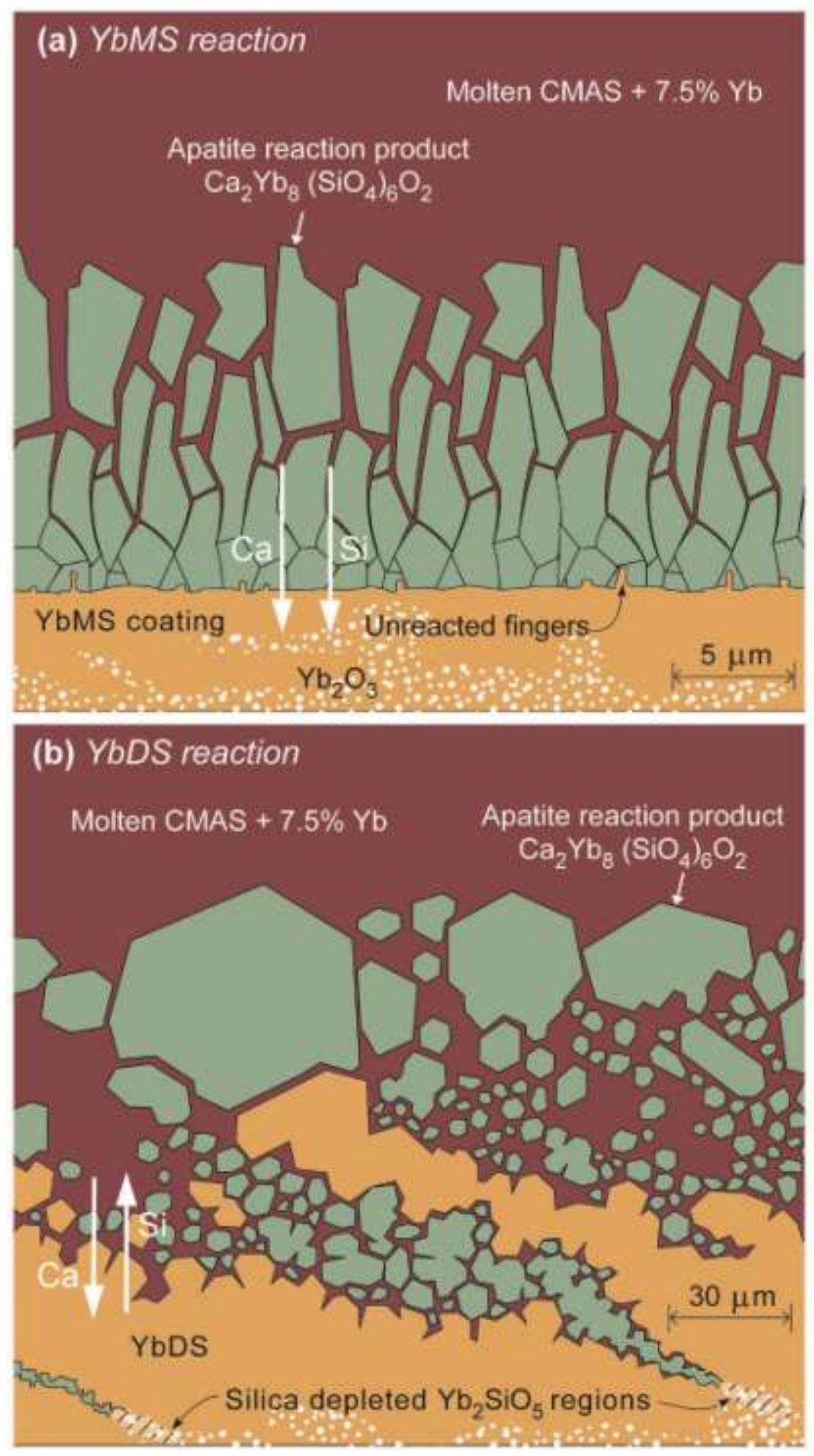

Figure 15. Schematics of the envisaged reaction mechanisms between CMAS and (a) YbMS and (b) YbDS APS coatings 
Table 1. The chemical compositions of the segregated particles and the matrix in the annealed YbMS/YbDS coating

\begin{tabular}{|c|c|c|c|}
\hline \multicolumn{2}{|c|}{ Composition (at. \%) } & Yb & $\mathrm{Si}$ \\
\hline \multirow{2}{*}{$\begin{array}{c}\text { Second phase } \\
\text { particles (dark) }\end{array}$} & In YbMS & 95.3 & 4.7 \\
\cline { 2 - 4 } & In YbDS & 62.5 & 37.5 \\
\hline \multirow{2}{*}{ Matrix (grey) } & In YbMS & 65.3 & 34.7 \\
\cline { 2 - 4 } & In YbDS & 47.1 & 52.9 \\
\hline
\end{tabular}

Table 2. The compositions (mole \%) of the CMAS melt near the reaction layer and bulk CMAS (columns in grey) for YbMS EBC system after different reaction times

\begin{tabular}{|c|c|c|c|c|c|c|c|c|c|c|}
\hline CMAS & \multicolumn{2}{|c|}{$\mathrm{CaO}$} & \multicolumn{2}{|c|}{$\mathrm{MgO}$} & \multicolumn{2}{|c|}{$\mathrm{AlO}_{1.5}$} & \multicolumn{2}{|c|}{$\mathrm{SiO}_{2}$} & \multicolumn{2}{|c|}{$\mathrm{YbO}_{1.5}$} \\
\hline Initial & \multicolumn{2}{|c|}{36.2} & \multicolumn{2}{|c|}{6.0} & \multicolumn{2}{|c|}{11.8} & \multicolumn{2}{|c|}{46.0} & \multicolumn{2}{|c|}{0} \\
\hline Saturated & \multicolumn{2}{|c|}{32.1} & \multicolumn{2}{|c|}{5.3} & \multicolumn{2}{|c|}{10.4} & \multicolumn{2}{|c|}{44.7} & \multicolumn{2}{|c|}{7.5} \\
\hline $1 \mathrm{~min}$ & 31.9 & 31.1 & 6.2 & 6.2 & 8.9 & 7.8 & 47.5 & 47.1 & 5.5 & 7.8 \\
\hline $4 h$ & 29.9 & 29.1 & 6.4 & 6.3 & 11.5 & 10.0 & 47.2 & 47.2 & 5.0 & 7.4 \\
\hline $24 \mathrm{~h}$ & 29.2 & 28.4 & 6.2 & 6.2 & 12.2 & 10.7 & 47.2 & 47.1 & 5.2 & 7.6 \\
\hline $100 \mathrm{~h}$ & 27.4 & 26.9 & 6.6 & 6.5 & 14.1 & 12.9 & 46.5 & 46.3 & 5.4 & 7.4 \\
\hline $250 \mathrm{~h}$ & 23.5 & 22.6 & 5.7 & 5.4 & 15.9 & 14.1 & 49.9 & 50.3 & 5.0 & 7.6 \\
\hline
\end{tabular}

Table 3. The chemical compositions of the apatite for $\mathrm{Yb}$ monosilicate and disilicate coatings reacted with CMAS.

\begin{tabular}{|c|c|c|c|c|c|}
\hline Composition (mole\%) & $\mathrm{CaO}$ & $\mathrm{YbO}_{1.5}$ & $\mathrm{SiO}_{2}$ & $\mathrm{MgO}$ & $\mathrm{AlO}_{1.5}$ \\
\hline YbMS apatite & 12.5 & 47.9 & 37.7 & 1.9 & 0 \\
\hline
\end{tabular}




\begin{tabular}{|l|l|l|l|l|l|}
\hline YbDS apatite & 12.4 & 47.0 & 38.5 & 2.1 & 0 \\
\hline
\end{tabular}

Table 4. The compositions (mole\%) of the CMAS melt near the reaction layer and bulk CMAS (columns in grey) for YbDS EBC system after different reaction times

\begin{tabular}{|c|c|c|c|c|c|c|c|c|c|c|}
\hline CMAS & \multicolumn{2}{|c|}{$\mathrm{CaO}$} & \multicolumn{2}{c|}{$\mathrm{MgO}$} & \multicolumn{2}{c|}{$\mathrm{AlO}_{1.5}$} & \multicolumn{2}{c|}{$\mathrm{SiO}_{2}$} & \multicolumn{2}{c|}{$\mathrm{YbO}_{1.5}$} \\
\hline Initial & \multicolumn{2}{|c|}{36.2} & \multicolumn{2}{|c|}{6.0} & \multicolumn{2}{c|}{11.8} & \multicolumn{2}{|c|}{46.0} & \multicolumn{2}{c|}{0} \\
\hline Saturated & \multicolumn{2}{|c|}{30.8} & \multicolumn{2}{|c|}{5.1} & \multicolumn{2}{c|}{10.0} & \multicolumn{2}{|c|}{46.6} & \multicolumn{2}{c|}{7.5} \\
\hline $1 \mathrm{~min}$ & 29.3 & 28.4 & 6.2 & 6.2 & 8.9 & 8.5 & 50.0 & 50.4 & 5.6 & 6.5 \\
\hline $4 \mathrm{~h}$ & 27.4 & 26.9 & 5.5 & 5.6 & 10.7 & 9.0 & 50.5 & 50.3 & 5.9 & 8.2 \\
\hline $24 \mathrm{~h}$ & 25.5 & 25.2 & 5.4 & 5.0 & 11.7 & 10.9 & 51.4 & 51.3 & 6.0 & 7.6 \\
\hline $100 \mathrm{~h}$ & 24.6 & 24.2 & 5.5 & 5.8 & 13.3 & 11.5 & 51.2 & 50.8 & 5.4 & 7.7 \\
\hline $200 \mathrm{~h}$ & 24.4 & 23.8 & 5.6 & 5.6 & 13.0 & 11.4 & 51.5 & 51.8 & 5.5 & 7.4 \\
\hline
\end{tabular}

